\title{
Aportaciones desde una propuesta de musicoterapia con adolescencia adoptada en acogimiento residencial en Bizkaia: de la improvisación musical clínica a la cohesión grupal
}

\section{Maider Abasolo Medina}

Conservatorio Municipal de Leioa

maiderabasolomedina@gmail.com

\section{Raúl Picó Jabato}

Fundación Amigó-Universidad de Deusto

rpico@fundacionamigo.org

\begin{abstract}
Azken hamarkadetan, babesgabetasun-egoeran dauden nerabeentzako egoitza-harrerak eta arreta psikologikoak kontzeptualizazio, espezializazio eta teknika berrietarantz - teknika artistikoak eta sorkuntzakoak horietako batzuk- eboluzionatu dute estatuan eta autonomia-erkidegoan. Kasuazterlan honek Bizkaian egoitza-harreran dauden bost neraberen talde-kohesioa aztertzen du, musikainprobisazio klinikoan oinarritutako musikoterapia bidez. Hogei saiotan zehar, saio bakoitzeko talde-inprobisazioen iraupena zenbat handitu den ebaluatu da, baita musika-sinkronia bera ere. Azterlanak agerian utzi du adopzio osteko eskuhartze terapeutikoaren elementu espezifiko batzuek pertsonen arteko erregulaziotik pertsona barruko erregulaziora igarotzeko lana erraztu dezaketela, baldin eta inprobisazio aske eta erreferentzialaren bidez pertsona horiek musikarekin, beren buruarekin eta besteekin konektatzen badute, bakoitzaren nortasuna, atxikimendu-estiloak eta bizipenak gorabehera.
\end{abstract}

\section{GAKO-HITZAK:}

Egoitza-harrera, adopzioa, nerabezaroa, musikoterapia, musika-inprobisazioa.
En las últimas décadas, el acogimiento residencial y la atención psicológica a la adolescencia en desprotección han evolucionado en el ámbito estatal y autonómico hacia nuevas conceptualizaciones y técnicas, algunas de tipo artístico-creativo. Este estudio de caso explora, mediante la musicoterapia basada en la improvisación musical clínica, la cohesión de un grupo de cinco personas adolescentes adoptadas en acogimiento residencial en Bizkaia. A lo largo de veinte sesiones, se ha evaluado el aumento en la duración de las improvisaciones grupales por sesión, junto con la sincronía musical. El estudio pone de manifiesto que existen elementos específicos de la intervención terapéutica postadoptiva que pueden facilitar el tránsito de la regulación interpersonal a la intrapersonal cuando, mediante la improvisación libre y referencial, estas personas conectan con la música, con ellas mismas y con las demás, a pesar de las diferentes personalidades, estilos de apego y vivencias individuales.

\section{Palabras Clave:}

Acogimiento residencial, adopción, adolescencia, musicoterapia, improvisación musical. 


\section{Introducción}

Son varias las orientaciones terapéuticas que cobran protagonismo en la atención psicológica actual. De hecho, en los últimos años las terapias alternativas no farmacológicas (García-Casares, Moreno-Leiva y García-Arnés, 2017) y las denominadas terapias cognitivo-conductuales de tercera generación (Moreno Coutiño, 2012) se aproximan de manera complementaria, comparten perspectivas y confluyen en estrategias de cambio de carácter indirecto, experimental y contextualista. Se ofrecen como una construcción de alternativas amplias y flexibles ante la estandarización de los tratamientos tradicionales. La terapia médica y la terapia artísticacreativa $^{1}$ pueden ser aliadas y coexistir en el espacio terapéutico ante problemas emocionales y de salud. La musicoterapia, en concreto, persigue objetivos terapéuticos a través de la música como herramienta de intervención, haciendo uso de diversas técnicas en torno a ella.

Con respecto a la atención psicológica estandarizada de niños, niñas y adolescentes en acogimiento residencial, existen alternativas de trabajo sugerentes e innovadoras a la hora de acceder a la "sala de valientes" (Barudy y Dantagnan, 2005; Barudy et al., 2014; Galán Rodríguez, 2014; Gonzalo Marrodán, 2010; 2015). De hecho, a lo largo del contacto directo en la consulta personal es donde pueden surgir y mantenerse dificultades de tipo reactivo a la adaptación o estáticas a la terapia tradicional, por todo lo que implica y puede ofrecer una psicoterapia como base de seguridad o inseguridad en lo vincular, terapéutico, integrador y reparador. Por tanto, un auténtico reto o una posible retraumatización que puede acompañar más fracaso, dolor, tiempo perdido y frustración para profesionales, familias y adolescentes, en concreto, para aquellos casos de personas menores de edad adoptadas que han transitado por múltiples servicios profesionales y han tenido que salir del domicilio familiar, regresando al sistema de acogida (Berástegui, 2003; 2005; 2007; 2017; 2018). Este fenómeno de segundas o terceras rupturas en la convivencia familiar a lo largo de la adolescencia adoptada (Rodríguez, 2017) necesita de una intervención intensiva "por partes" en torno a la estabilización, sintonización y sostenimiento de las relaciones tanto interpersonales como intrapersonales. Por tanto, un encuadre específico de protección a la infancia y adolescencia, bajo una modalidad de acogimiento residencial que cubre necesidades socioterapéuticas y de intervención en crisis, vinculado a un determinado proceso familiar, institucional y convivencial.

En este sentido, este artículo recoge una propuesta experimental de terapia a través de la música,

${ }^{1}$ Los lenguajes artísticos que se utilizan como terapia pueden ser la música, las artes visuales, la danza-movimiento y la expresión dramática, es decir, arteterapia, musicoterapia y teatroterapia (MateosHernández, 2011). dirigida a cinco adolescentes vizcaínos en acogimiento residencial, con el objetivo principal de favorecer la cohesión del grupo a través de la improvisación clínica, medida por medio de la producción y duración de las ejecuciones musicales espontáneas del grupo, además de la sincronía musical que ocurre en ellas. Este objetivo de favorecer la cohesión grupal (que quizás en el trabajo con otras poblaciones no es el eje central de la intervención, sino un primer paso para lograr otros objetivos terapéuticos) resulta significativo, teniendo en cuenta la desorganización en los estilos de apego y las alteraciones de conducta de esta población, como consecuencia de la acumulación de elementos traumáticos individuales sin resolver, dismadurez y labilidad emocional, además de dificultades para la mentalización, lo cual les hace muy difícil confiar, empatizar y escuchar al otro, siendo el trabajo en equipo una incertidumbre para ellos mismos (Lieberman y Knorr, 2007; Lecannelier, 2014).

\section{De la adopción al acogimiento residencial: tránsito entre las medidas de protección y la ruptura de la convivencia familiar}

Resulta inevitable asociar al fenómeno de la infancia y adolescencia desprotegida la vigencia del modelo de buen trato, desarrollo infantil y cuidado familiar inherente a los padres y a los poderes públicos (Barudy y Dantagnan, 2005; Vázquez-Pastor, 2019), un sistema mixto en el que participan familia, entidad pública y los propios adolescentes. El deber de la protección familiar es un principio constitucional y el interés superior de la persona menor de edad es un principio rector de la actuación de los poderes públicos. En este sentido, los diferentes tránsitos que se producen a lo largo del ciclo vital, unidos a acontecimientos de carácter individual o grupal (cambios de colegio, amistades, relaciones de pareja, pérdidas en la familia, mudanzas, enfermedades, trabajo, etc.) suponen elementos significativos en el proceso de construcción identitaria de las personas, especialmente, a lo largo de los periodos sensibles de desarrollo de la personalidad como pueden ser la primera infancia y la adolescencia (Sepúlveda, 2010).

Hoy día, la adopción se incluye dentro de las denominadas "nuevas parentalidades" en contextos cambiantes (Fernández-Rasines y Bogino, 2013). Esta medida de protección familiar mayoritariamente exitosa para padres, madres, hijos, hijas y demás familia extensa, también acompaña un porcentaje significativo de familias con alta inestabilidad convivencial, conductual y relacional, con demanda de ayuda de la entidad pública e incluso con situaciones extremas de adopciones que se rompen. Esto puede implicar un cese definitivo o temporal en la convivencia familiar y el regreso de estas personas menores de edad al servicio de infancia (Berástegui, 2017; Palacios et al., 2018; Palacios, 2019). El aumento de la investigación en torno a las 
adopciones internacionales ha permitido estimar la incidencia de las rupturas en la adopción. Por ejemplo, en Estados Unidos supone el 10\%-25\%, mientras que en Europa los porcentajes se sitúan en el 2,5\% en Países Bajos, $4 \%$ en Suecia, 3,8\% en Inglaterra, $1,8 \%$ en Italia y $1,5 \%$ en España (Jeannin, 2018). En varias comunidades autónomas españolas el porcentaje de menores adoptados alcanza el $1 \%$ de la población infanto-juvenil. En Euskadi, concretamente, uno de cada cien niños y niñas ha sido adoptado y el fracaso en la adopción se aproxima a un $8 \%$ (Agintzari, 2005; 2006; 2008; Loizaga, 2009; Rodríguez, 2017). Se trata de un fenómeno emergente a escala internacional, estatal y autonómica, aunque no es representativo de la amplia y diversa realidad de casos y situaciones con relación a la dificultad en la adopción. De hecho, en Estados Unidos (Smith, 2014) prevalecen porcentajes de entre el $20 \%-30 \%$ de familias adoptivas cuyo día a día atraviesa por situaciones de alta conflictividad dentro del propio domicilio familiar. La investigación estatal y autonómica (Berástegui, 2017; Fernández Rivas et al., 2013) apunta hacia una sobrerrepresentación de este colectivo en centros de acogida para adolescentes y en servicios de salud mental. Las crisis en la adopción y el fenómeno de la ruptura de la convivencia suelen darse mayoritariamente al inicio de la preadolescencia (Paniagua, Palacios y Jiménez-Morago, 2019). Asimismo, el alejamiento familiar y el reingreso de esta población adoptada en el acogimiento residencial pueden implicar, dentro del escenario de la postadopción, una intervención intensiva de carácter socioterapéutico vinculada a la tríada familia-menor de edad-red profesional en cuanto a la permanencia relacional discontinua o discontinuidad en adopción (Evan B. Donaldson 2004; Rushton, 2004; Smith, 2014; Rolock, 2015).

El tránsito interrumpido en la convivencia familiar bien con la familia de origen, con la familia por adopción o con la familia institucional, puede desorganizar el sistema de apego, alterar el desarrollo armónico e integral de la personalidad e incidir de manera disfuncional, en mayor o menor medida, en variables asociadas a nivel personal, familiar, ambiental e incluso profesional. La transición de la adopción al acogimiento residencial resulta un periodo de enlace sensible por su acomodación, acumulación de cambios imprevisibles, experiencias de fracaso y rupturas de contacto de cara a la estabilidad emocional, identitaria, relacional y jurídica de las personas menores de edad (Brodzinsky y Smith, 2019). Sin olvidar cómo afecta a la elaboración de una narrativa coherente sobre su historia vital, al enfoque de derechos (adopción abierta, acceso a los orígenes e identidad, etc.) y al nivel de bienestar, satisfacción, calidad de vida, autonomía y tránsito a la vida adulta.

La vida en las instituciones es un factor de riesgo para el apego inseguro y desorganizado, siendo los menores institucionalizados en edades tempranas los que presentan mayores tasas de desorganización
(Lionetti, Pastore y Barone, 2015). Ahora bien, el acogimiento residencial no se convierte en una experiencia negativa y estática para todas aquellas personas menores de edad que lo han necesitado. De hecho, existen estudios que muestran una valoración positiva por parte de los propios menores, aunque empeora si aumenta su tiempo de estancia (Bravo y Fernández del Valle, 2001; Cabrera, 2007). Esta conclusión remarca lo importante de acotar y temporalizar las intervenciones, metodologías y espacios residenciales a las nuevas realidades y necesidades emergentes, especialmente, cuando se rupturizan o se interrumpen las relaciones familiares o de crianza adoptiva.

\section{Adolescencia, música y musicoterapia}

A lo largo de este proceso de transición crucial de cambios físicos, emocionales, cognitivos y sociales, se va consolidando la identidad personal, sexual y relacional de la persona menor de edad, influida por las historias afectivas familiares, ambientales y por los aprendizajes realizados a lo largo de la vida. El vínculo de apego familiar biológico o por adopción sigue siendo de gran importancia, aunque al inicio de la pubertad se produzca la separación de los modelos parentales y se inicie el acercamiento hacia el grupo de iguales (López Sánchez, 2015; Palacios, 2017). Para algunos adolescentes que carecen de experiencias de buen trato (Barudy y Dantagnan, 2005), puede resultar complejo poner en palabras su mundo interior, puesto que los sentimientos pueden estar bloqueados, preparados para sobrevivir en modo de defensa o disociación, con dificultades para mentalizar en su propio estado y el de los demás. De hecho, la intervención psicológica actual y el tratamiento del trauma (Janet, 1889) siguen siendo un reto para los terapeutas, los adolescentes y las familias (Gonzalo Marrodán, 2010; 2015; Palacios, 2019).

Mediante la musicoterapia, la música puede abordar el trauma de un modo no invasivo, activo y receptivo, ofreciendo herramientas y técnicas de afrontamiento, que favorecen resignificar experiencias, reducir síntomas, identificar disparadores, ajustar comportamientos sociales y, en definitiva, promover bienestar y calidad de vida en las personas (Kern, 2011). El poder de la música en el abordaje terapéutico viene dado por la influencia que ejerce en los seres humanos, siendo utilizada para satisfacer las necesidades emocionales, cognitivas y sociales a lo largo del ciclo vital, independientemente de la edad, cultura o nivel social (North, Hargreaves y O’Neill, 2000). La naturaleza no verbal de la música facilita la comunicación y la expresión, presentándose como una herramienta valiosa y de gran utilidad para el tratamiento de una amplia realidad de problemáticas. Una alternativa en la confección del vínculo terapéutico de seguridad y en la promoción de la satisfacción vital, además de la salud física y mental de las personas (Andrade, 2005). 
En la etapa adolescente, la música se convierte en un canal de comunicación que habla directamente de las emociones. Wells y Hakanen (1991) sostienen que las letras de las canciones que escuchan reflejan la intensidad emocional que viven en su vida cotidiana. Además, identifican diversos beneficios en la música, como una forma de relajación y escape de la realidad, contacto con uno mismo, pensamiento creativo, conexión con las experiencias personales, acceso al inconsciente y herramienta para comunicarse con los demás (McFerran, Roberts y O'Grady, 2010). Múltiples utilidades que tienen que ver con lo que sucede en el cuerpo humano al escuchar o ejecutar música. A diferencia de otras actividades, que ponen en funcionamiento únicamente zonas específicas del cerebro, la música lo estimula por completo (Sáez, 2010; Mosquera, 2013), involucrando características neuroanatómicas y fisiológicas (Limb y Braun, 2008), promoviendo la plasticidad neuronal que permite modelar aquellas redes neuronales que pueden estar comprometidas (Sihvonen et al., 2017). Así, el hecho musical regula las funciones cerebrales, circulatorias, respiratorias, nerviosas, etc.; favorece la relajación a través de la secreción de péptidos y endorfinas que actúan en el sistema nervioso central y periférico; modula los niveles de dopamina y serotonina encargados de las funciones motoras, del comportamiento, de la cognición, de los estados de ánimo y del sueño; y estimula el equilibrio, la coordinación y la propia conciencia del cuerpo y del espacio, mejorando el tono muscular cuando se acompaña de movimiento (Yánez, 2011).

En lo referido a la intervención con adolescentes, se han observado avances en el área afectivo-emocional, social, cognitiva y de la comunicación. A nivel afectivoemocional, la musicoterapia disminuye la tensión, la agresividad y la ansiedad, aporta seguridad y produce un aumento de la tolerancia a la frustración (Layman, Hussey y Laing, 2002). Además, la terapia musical en grupo permite a las personas valorar no solo su música, sino también la de los otros, al mismo tiempo que sienten que son escuchadas, evocando experiencias emocionales conectadas con sus historias vinculares, experimentando intercambios no verbales entre sus miembros y compartiendo sentimientos que favorecen el autoconocimiento y la consciencia de los sentimientos de los demás (Garaigordobil, 1998; Rickson y Watkins, 2003; Chen et al., 2014; Padilla et al., 2017; Porter et al., 2017). En este sentido, McFerran, Roberts y O'Grady (2010) apuntan que los adolescentes tienden a sentirse mejor si tienen oportunidades de expresar su pérdida de manera creativa junto con sus iguales, permitiendo que se libere la energía reprimida asociada a su dolor en la participación musical. Esto se produce cuando se ha logrado la sensación de seguridad y comunidad en el grupo, siendo la pérdida de cada uno de ellos aceptada por el conjunto, aumentando la cohesión del grupo y desarrollándose vínculos entre sus miembros que les ayudarán a fortalecer la motivación hacia el cambio y el aprovechamiento del proceso terapéutico (Zahonero, 2007; Fernández-Batanero y Cardoso, 2016).
En el área social, la musicoterapia aporta una experiencia estructurada, fomentando la autorregulación y ofreciendo experiencias de interrelación, disminuyendo así las conductas inadecuadas, aumentando la conciencia social, la cooperación, las conductas prosociales y la cohesión social (Zahonero, 2007; Benedito, 2010). Rickson y Watkins (2003) señalan que en los menores con déficit de atención severos dicha terapia ayuda al desarrollo de relaciones positivas con sus iguales, resultando efectiva para la detección y prevención de adicciones, así como para la reducción de conductas hostiles. Se observan mejoras cognitivas, ya que favorece el incremento de la atención, el aprendizaje y la memoria, estimulando la imaginación y la motivación (Layman, Hussey y Laing, 2002; Gold, Voracek y Wigram, 2004; Benedito, 2010).

Por último, en el área de la comunicación, la terapia musical aumenta la capacidad de expresión y desarrolla habilidades comunicativas y de creatividad. Estos aspectos se pueden ver multiplicados cuando se trata de trabajo grupal, puesto que favorece la interacción entre los miembros del grupo, la verbalización de ideas y la aceptación de las ideas de los otros. Todo ello aporta oportunidades afectivas mutuas, crea empatía entre sus miembros y mejora el autoconcepto y la autoestima (Garaigordobil, 1998; Benedito, 2010; Tomlinson, Derrington y Oldfield, 2012; López Sánchez, 2015; Porter et al., 2017).

\section{Improvisación musical clínica y cohesión grupal}

La improvisación clínica es considerada como una combinación de sonidos creados por una persona o grupo de personas en un entorno de seguridad, de acuerdo con un marco de actuación y un modelo concreto, en el que la figura del musicoterapeuta acepta la música o sonidos de las personas, ya sea en la propia ejecución espontánea o en cualquier otra técnica o dinámica que se emplee, puesto que la creación musical clínica no busca un objetivo estético sino terapéutico (Bruscia, 1997; 2010; Wigram, 2005). De hecho, el acto creativo improvisado, no planeado ni ensayado, obtiene según el método Orff (1930) una representación cortical en el área de procesamiento de la información, donde se alojan la motivación y el lenguaje pre y postverbal, afirmando que, en el acto de improvisación, participan pocas acciones conscientes y un número considerable de acciones inconscientes, convirtiéndose en improvisación motriz, gestual, verbal y lingüística no codificada (Díaz, Martínez y Revelo, 2011). A su vez, Jauset (2014) y Punkanen (2011) concluyen que en la aplicación de la improvisación se integra lo corporal, lo emocional, lo social y los diferentes niveles cognitivos al unísono. Esta producción musical creada conecta de manera directa con las emociones y los recuerdos, pudiendo acceder a partes no conscientes amenazantes y dolorosas, y posibilitando su acercamiento hacia la 
transformación o el cambio (Swallow, 2002). De este modo, la improvisación clínica, a modo de objeto transicional (Winnicott, 1994), ofrece, de una manera respetuosa hacia la persona, una herramienta creativa e indirecta para el alcance y la expresión de sentimientos más profundos con el terapeuta o con el terapeuta y el grupo. También puede simbolizar un medio para representar sensaciones, ideas, imágenes, fantasías, recuerdos o situaciones relacionales intra e interpersonales dentro del grupo, que puede revelar material no-consciente para actuarlo y a partir de ahí, favorecer habilidades relacionales, creativas, perceptuales y cognitivas (Hiller, 2009; Punkanen, 2011).

De esta manera, cada sonido producido por la persona expresa algo acerca de ella, refleja y proyecta cómo organiza sus mundos internos y externos; y favorece, a través de diferentes técnicas de creación y expresión, aproximar directa y/o indirectamente el evento traumático del pasado, los tránsitos y/o las rupturas acumuladas (Amir, 2004). En este sentido, no deja de ser una alternativa que permite explorar, expresar libremente y escuchar a los demás de manera simultánea, entrenar la presintonización emocional de los sentimientos positivos y negativos, así como de posibles imágenes, flashbacks o recuerdos "agarrados" a acontecimientos vitales acumulativos dolorosos, más allá del uso de la palabra (Ansdell, 1990; McFerranSkewes, 2003; McFerran, 2010; Chen et al., 2014). Todo ello favorece la liberación de carga emocional mediante un proceso de expresión no verbal, construyendo una alternativa optimista hacia nuevas líneas futuras de trabajo terapéutico (Pérez-Vich, 2008; McFerran, 2010).

El uso de la terapia grupal con adolescentes es relevante por la importancia que adquiere la identificación, la pertenencia al grupo y la socialización. La interacción entre sus miembros permite descentralizar la atención en uno mismo y el estilo de trabajo terapéutico ayuda a generar un clima grupal, aportando un campo interpersonal mayor en el que cada miembro aporta elementos psicoterapéuticos a los demás y en el que cada uno recibe del conjunto (Vinogradov y Yalom, 1996). También promueve la comunicación del grupo a través de la escucha activa y de la comunicación asertiva, desarrolla las relaciones de ayuda y de cooperación, y puede ser una oportunidad para la proyección, el acompañamiento y la familiarización de técnicas de resolución de conflictos (Torras de Beá, 1996; Garaigordobil, 1998; Rodríguez Díaz, 2006; Zahonero, 2007). Asimismo, Pavlosky (1987) considera que, aunque no puede ser sustitutiva de la terapia individual, en todo tratamiento psicoterapéutico con niños, niñas o adolescentes, debería incluirse alguna experiencia grupal. Este aspecto resulta interesante en cuanto al éxito de determinadas iniciativas terapéuticas de abordaje grupal con relación a las familias adoptivas y a sus hijos e hijas, sobre todo, a la hora de aproximarse a cuestiones identitarias, experiencias artístico- creativas, conflictos, preocupaciones comunes y encuentros o intercambios (Betts, 2003; Fernández Rivas et al., 2014; Berástegui, 2017; Jeannin, 2018; Palacios, 2019).

La cohesión de grupo es un primer paso para conseguir otros objetivos terapéuticos (Yalom y Leszcz, 2005). Resulta interesante aproximar la cohesión grupal ante los problemas conductuales, las dificultades para trabajar en equipo, la desconfianza en los demás, los bajos niveles de empatía y los inconvenientes para implicarse en las relaciones afectivas con distancia emocional de los otros. Todo ello como resultado de haber podido experimentar numerosas pérdidas a lo largo de la vida, que no han sido elaboradas como para poder expresar sentimientos, regularse emocionalmente e incluso haber desarrollado estrategias de evitación y supervivencia, complicando el acceso a ellos (Díaz Atienza y Blánquez, 2004; Berástegui, 2005; Fernández-Daza y Fernández-Parra, 2013).

En este sentido, para alcanzar esta cohesión es necesario proporcionar seguridad y apoyo al grupo, que permita que se pueda confiar y se puedan desplegar los mecanismos de defensa para poder poner a prueba y experimentar un sentimiento de pertenencia, estimular la lealtad, el compromiso entre los miembros del grupo, la complicidad en las relaciones, el desarrollo de las tareas y la responsabilidad individual y colectiva con relación al grupo. Estos factores favorecen el desarrollo de relaciones de ayuda mutua, colaboración, apoyo, solución de problemas y afrontamiento de conflictos intragrupales (Alzate et al., 1997; Sawyer, 1999; Campos Vidal, 2000; Vivas, Rojas y Torras, 2009; Parra-Ramajo, 2012). Así, tanto la conexión emocional del grupo como la experiencia de su efectividad contribuyen al desarrollo de la cohesión, la cual se representa de manera más clara en los procesos no verbales (Yalom y Leszcz, 2005), puesto que el grupo experimenta y se expresa de manera espontánea y sin preparación, obteniendo como resultado creaciones musicales que surgen de las acciones de cada uno, se unifican y funcionan conjuntamente. No existen expectativas respecto a la música; lo fundamental son las fluctuaciones y los cambios que van surgiendo, la manera en la que se escuchan entre ellos, el modo en el que crean musicalmente, colaboran con el grupo y llegan a acuerdos para resolver los posibles conflictos (Peralta, 2011).

\section{Objetivos}

Esta propuesta experimental de musicoterapia en grupo explora y se acerca a la realidad grupal e individual de cinco adolescentes que conviven en un centro de acogida. Una propuesta abierta, con una metodología adaptada y una técnica flexible para unir música, emociones e improvisación, y así poder observar los procesos de tránsito de la regulación interpersonal a la intrapersonal en la conexión con 
la música, con ellos mismos y con los demás. Los objetivos directos e indirectos de esta propuesta de terapia musical son los siguientes:

- Desarrollar la cohesión grupal y trabajar en afianzar el vínculo terapeuta-grupo, así como el vínculo entre los miembros de dicho grupo.

- Promover las habilidades sociales y el aprendizaje emocional.

- Presintonizar emocionalmente y favorecer la expresión, verbalización y comunicación.

- Aumentar la autoestima y el respeto a los demás.

- Reducir conductas agresivas y mejorar el autocontrol y la impulsividad.

- Ayudar a descubrir las habilidades y potencialidades del grupo y de cada individuo en particular.

\section{Metodología}

Esta intervención toma como punto de partida las necesidades y características de cinco adolescentes y adapta una metodología concreta al espacio terapéutico, a la propia técnica, a la terapeuta, al grupo y a su contexto (Perkins y Graham-Bermann, 2012). La improvisación musical clínica, de tipo libre y/o referencial, es la técnica utilizada de manera mayoritaria en este trabajo, el cual también se apoya en herramientas técnicas como la creación de canciones o songwriting, el movimiento, la pintura o los procesos de reflexión y silencio. Un enfoque ecléctico de la musicoterapia conformado por técnicas y dinámicas diversas de los distintos modelos teórico-prácticos (Arnason, 2002; Gold, Voracek y Wigram, 2004). Las técnicas experimentadas en esta propuesta son activas $\mathrm{y} / 0$ receptivas, es decir, de participación real y creación musical, así como de escucha musical y respuesta a la experiencia de manera silenciosa, verbal o de otro modo (Bruscia, 1997; Grocke y Wigram 2008).

El objetivo de la creación musical espontánea grupal es proyectarse al exterior a través de la música y de los instrumentos, incluso modularse con relación a un tema, una idea, una emoción, etc. De hecho, escuchar a lo largo de las sesiones la música, al grupo, al terapeuta o de manera individual la música que hace otro, puede implicar procesos de reflexión, improvisación, reactividad y silencio. La música que surge puede ser una expresión de la identidad, personalidad y carácter de cada uno de los miembros, es decir, como una creación del ser humano, que le permite verse a sí mismo en la música que produce y explorar aspectos inconscientes o conscientes sobre sentimientos, acontecimientos y relaciones específicas (Wigram, Nygaard y Ole, 2005; Bruscia, 2010). De ahí que la improvisación musical clínica puede convertirse en el punto de partida para aproximarse a síntomas, resistencias, bloqueos o problemas terapéuticos.
La historia sonora de cada miembro del grupo es relevante en esta intervención, ya que aporta mucha información sobre los gustos musicales y sonidos que producen rechazo, así como recuerdos que resuenan con determinadas músicas, instrumentos, melodías y voces. Además, la escucha consciente de una canción relacionada con su identidad sonora y la posterior reflexión de la letra se convierte en una gran herramienta cuando existen dificultades para poner en palabras la realidad que viven o cómo se sienten (Montánchez y Orellana, 2015). La creación de canciones, o songwriting grupal, bien sea modificando la letra de una canción ya compuesta o con la creación íntegra, ayuda en la estimulación, relajación, soporte y seguridad, facilitando el contacto con los procesos de pensamiento inconsciente, la proyección de sentimientos en la música y el ensayo de habilidades sociales para el trabajo en equipo (Baker y Wigram, 2005; Schapira et al., 2007).

Esta propuesta experimental no aborda un análisis exhaustivo de la música, ni la elección instrumental de los miembros del grupo. Se centra en el análisis de la cohesión grupal y de la sincronía musical en las diferentes improvisaciones, de acuerdo con el criterio e interpretación técnica del musicoterapeuta para su identificación, reconocimiento y selección. El cuerpo de las investigaciones coincide en señalar lo complejo y enriquecedor que consiste aproximarse a objetivar el fenómeno de la cohesión grupal, puesto que son escasos los estudios que presentan metodologías y técnicas para su medición y generalización de resultados (Kaplan y Sadock, 1993, cit. en Kaser, 1993; Hakes, 1996; Skewes, 2001; Yalom y Leszcz, 2005).

Desde lo musical, esta investigación explora la premisa de que la cohesión grupal sucede cuando el grupo trabaja de manera conjunta bien activa o receptivamente en las diferentes improvisaciones (Kaplan y Sadock, 1993, cit. en Kaser, 1993). Esta cohesión de grupo se mide a través de la sincronía musical, es decir, de la concurrencia simultánea de sonidos, movimientos o acciones, que suceden en un marco temporal a partir de un patrón rítmico conjunto (Malbrán, 2007). Esto se representa a través de elementos musicales como la pulsación, el ritmo, el tempo, las dinámicas, el movimiento, el silencio, los reflejos musicales entre cada uno de los miembros, y cuando el grupo es capaz de finalizar la música conjuntamente. Destaca la pulsación como un elemento que proporciona seguridad y estabilidad a la música y al grupo. Además, sirve como apoyo y contención para poder ir construyendo y sincronizando otros elementos musicales, que confluyen en la improvisación y permiten conectarse con la experiencia, para ir desarrollando el diálogo musical y las relaciones grupales (Lee, 2000; Schögler, 2003; Bruscia, 2010).

Lograr este pulso común supone que cada miembro no está escuchando solo su propia música, sino también la del conjunto para tratar de adaptarse 
a ella. La estructura de la obra que el grupo va creando de manera conjunta otorga un comienzo, un desarrollo y un final. Cada propuesta rítmica, melódica, dinámica o de tempo realizada por algún miembro del grupo es recogida y desarrollada por el propio grupo. La duración de las improvisaciones y la cantidad de estas por sesión cuantifica la conexión que tiene el grupo con los compañeros y con la música. Por lo tanto, para que todo ello suceda resulta fundamental un alto nivel de escucha del grupo, de atención y de capacidad para asimilar los cambios, imprevistos o dificultades.

La recogida de la información a lo largo del proyecto se realiza a través de la grabación en audio de las sesiones ${ }^{2}$, junto con el diario de sesión, las impresiones del terapeuta y las creaciones e improvisaciones musicales grupales e individuales. El análisis metodológico de la información es mixto, combinando criterios cuantitativos y cualitativos, ya que estudia comparativamente la duración, la cantidad de las improvisaciones musicales grupales por sesión, su evolución y la sincronía musical, además del registro de los comentarios de cada adolescente y las observaciones del musicoterapeuta en los siguientes ámbitos educativos: motor, emocional, cognitivo, comunicativo, social y musical (Del Barrio, Sabbatella y Brotons, 2019). Por último, y no menos importante para llevar adelante el proceso de intervención, está la acomodación de esta propuesta experimental al día a día de un centro de protección de menores, a las familias, a sus hijos e hijas y al conjunto de profesionales y equipos intervinientes de la red: comunicación, presentación del proyecto y objetivos, consentimientos informados, protocolos de confidencialidad de las familias tutores-legales y adolescentes, coordinación, supervisión técnica, análisis de las creaciones musicales y aportaciones. Esta iniciativa se presenta a los miembros del grupo como una oportunidad para conocer mejor al grupo y a ellos mismos y experimentar a través de la música, más allá de hacer hincapié en "psicologizar" o "terapeutizar" la propuesta experimental (Ferrandis, 2017).

En este sentido, antes y después de cada sesión semanal el grupo es acompañado por la figura de un educador/a social del hogar de acogida hasta el espacio de musicoterapia. Además, la figura técnica del musicoterapeuta ejerce un rol facilitador, sensible, reforzador, empático y seguro hacia el grupo, las personas implicadas, el espacio terapéutico, las sesiones y el setting de instrumentos. Esto conlleva una comunicación clara, sencilla y predecible con relación a la coordinación, estructura de las sesiones, inicio, duración, planificación y despedida o cierre hacia el grupo de adolescentes, familias y profesionales. La figura del terapeuta musical pondera al inicio un manejo moderado hacia la conversación, facilitando el acercamiento y la exploración del grupo hacia la

${ }^{2}$ Las sesiones 3 y 7 no se grabaron por problemas técnicos, aunque sí fueron descritas en el diario de sesión. improvisación musical mediante un rol segurizante, sintonizado, paciente y perseverante (Bruscia, 2010).

\section{Descripción del caso clínico}

\subsection{El grupo de adolescentes}

Este proyecto se dirige a un grupo de familias adoptivas con hijas e hijos en el sistema de protección de menores de Bizkaia, a través de la delegación de la guarda. La propuesta de intervención cuenta con la aceptación, interés y autorización de las familias como tutores legales, el Servicio de Infancia perteneciente a Diputación Foral de Bizkaia, Fundación Amigó, la musicoterapeuta formada en el Instituto Música, Arte y Proceso y los adolescentes. El grupo lo forman una chica y cuatro chicos con edades comprendidas entre los 16 y los 17 años. De la adopción nacional proceden dos varones y el resto de la adopción internacional. Residen en un mismo hogar de acogida específica para adolescentes con problemas de vinculación y con experiencias de ruptura de adopción. Además, presentan inestabilidad en la relación familiar antes de la preadolescencia, ingresos puntuales en psiquiatría infanto-juvenil, interconsulta psiquiátrica, seguimiento farmacológico y discontinuidad en el tratamiento psicológico habitual.

Participan de las sesiones sin necesidad de tener conocimientos previos de música o manejo de instrumentos musicales. Cada participante solicita recibir información de los resultados y acepta que se puedan utilizar las creaciones musicales improvisadas con fines formativos y de investigación. Al finalizar la intervención, cada participante recibe un pendrive con las diferentes improvisaciones realizadas. Se establece la posibilidad de acceder a una selección de estas a través de un acceso codificado a un sitio web, previa solicitud y justificación a los autores de este artículo. Por tanto, se garantiza el tratamiento respetuoso de dicha información, la confidencialidad, la preservación de la intimidad y la ética en la intervención, junto con el adecuado tratamiento, codificado y uso profesional de dichas creaciones artísticas improvisadas.

\subsection{Temporalización, 'setting' y espacio de trabajo}

Entre los meses de enero y junio de 2018 se desarrollan un total de veinte sesiones con una hora de duración semanal, en un espacio normalizado de uso público integrado en la comunidad, diferente del hogar de acogida y reservado para esta finalidad. El grupo viene acompañado de un educador/a social del hogar de acogida tanto al inicio como al final de las sesiones, que se realizan entre los adolescentes y la musicoterapeuta.

El setting de instrumentos está compuesto por un piano digital, un xilófono alto, un xilófono soprano, cuatro baquetas, una guitarra española, tres djembes, 
unas cajas flamencas, dos panderos, dos panderetas, dos sonajas, un agogó, una cabasa, unas claves, dos güiros, dos triángulos y cinco maracas. Dos alfombras delimitan el setting de instrumentos y alrededor de estas las sillas para cada miembro del grupo. Un total de siete sillas, dos dispuestas en el piano y las cinco restantes rodeando el setting. Se incluyen materiales fungibles como: folios, cartulinas, pinturas, rotuladores, ceras, etc., además de un altavoz digital para reproducir música y una grabadora de audio para registrar las sesiones. La sala donde se realizan las sesiones es amplia, con ventanales abiertos a zona verde, con gran cantidad de luz exterior y un cuarto de baño cercano. No se perciben sonidos que perturben el espacio terapéutico.

\subsection{Proceso terapéutico}

\subsubsection{Fases del proceso por sesiones}

Tras la intervención, revisión y posterior análisis, surgen varias fases resultantes del proceso de intervención en su conjunto. Con relación a las sesiones, la mayoría transcurren en tres partes diferenciadas, con caldeamiento de inicio, desarrollo y despedida o cierre. Con respecto a las fases del proceso, la fase de valoración agrupa las seis primeras sesiones, lleva por título “Acercándonos a lo desconocido" y está basado en una reflexión de Rothenberg sobre el uso de la técnica de la improvisación con adolescentes: "[...] the improvisation is about stepping into the unknown" (McFerran, 2010: 166). La segunda fase comprende un total de once sesiones (de la 7 a la 17, ambas incluidas) y entra de lleno en la terapia a través de la música. En esta fase, "Las heridas gritan" recuerda la obra de la autora Cathy Caruth (1996: 4) a propósito del trauma y la herida que no deja de gritar en silencio. Por último, “Colocando las despedidas" es la fase que engloba las tres últimas sesiones (de la 18 a la 20).

Para la descripción del proceso terapéutico se tienen en cuenta aspectos propios del análisis de las sesiones con relación al inicio del proceso, las creaciones musicales, la asistencia, la duración, la estructura de cada sesión, las incidencias y su progresión, además de una parte cualitativa con testimonios de los miembros del grupo en sesión. También son relevantes las valoraciones de la musicoterapeuta en el diario de sesión. Por último, la evaluación de los resultados analiza de una manera más cuantitativa la información sobre la producción de las improvisaciones, cantidad, duración, cohesión de grupo y sincronía musical.

\subsubsection{Descripción del proceso terapéutico}

\section{FASE dE VALORACIÓN. “ACERCÁNDONOS A LO DESCONOCIDO” (SESIONES 1-6)}

Esta fase de inicio contempla seis sesiones, a pesar de que Bruscia (2010) recomienda un margen comprendido entre dos y cuatro sesiones para este periodo de valoración inicial. La primera y la tercera sesión resultan ser sustancialmente significativas con relación a los primeros pasos y dinámicas. En esta fase la asistencia por parte de los miembros del grupo es regular y puntual, excepto en la quinta sesión, en la que no acuden tres integrantes ( $\mathrm{S}_{1}, \mathrm{~S}_{2}$ y 4 ).

\section{Primera Sesión: “iVete con la música a otra parte, pero quédate!"}

El grupo entra por primera vez en el espacio terapéutico como si se tratara de una carrera de obstáculos. Se apresuran por coger los instrumentos, acercarse a ellos y tocarlos compulsivamente sin parar de moverse, gritar y fantasear sobre cómo se tocan. Una puesta en escena donde las voces, los insultos, la falta de diálogos y las interrupciones muestran quién toca más fuerte por encima del resto. En resumen, una serie de conductas evitativas y ambivalentes, en forma de mensajes de rechazo y aceptación hacia el inicio de este proceso de intervención.

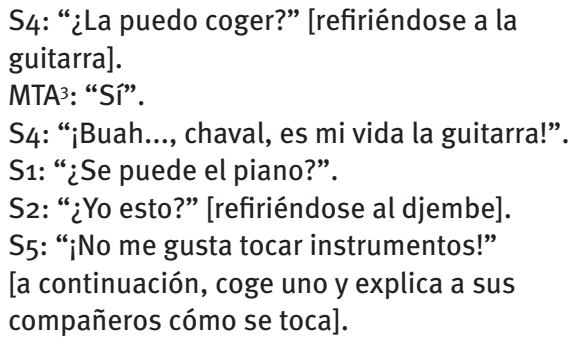

Cuando la terapeuta musical encuentra el espacio para intervenir, traslada que estos encuentros son una oportunidad para conocerse a través de la música y sugiere qué se puede realizar en las siguientes sesiones. Las primeras ideas y comentarios surgen de $\mathrm{S}_{2}, \mathrm{~S}_{3}$ y $\mathrm{S}_{4}$ sobre la posibilidad de hacer una canción y tocarla juntos, mientras que $\mathrm{S}_{1}$ y $\mathrm{S}_{5}$ discuten entre ellos con comentarios ofensivos. La musicoterapeuta recoge las primeras frases y palabras del grupo y las traslada a lo musical desde el piano. A partir de aquí surge un tarareo, un leve tocar de los instrumentos e incluso un posible título para la canción.

En el cierre de la sesión se inicia la primera improvisación espontánea, con una duración de 1 minuto y 51 segundos. Resulta desordenada, de tempo agitado y con predominio rítmico. A lo largo de la sesión y durante la improvisación musical libre, cada uno de los miembros del grupo habla permanentemente por encima de la música. Sin embargo, todo el grupo participa en lo musical con diferentes instrumentos, excepto $\mathrm{S}_{5}$, que se introduce en la creación, en primer lugar por medio de percusión corporal y de silbidos, y finalmente

\footnotetext{
${ }^{3}$ Se utiliza la forma abreviada MTA para referirse a la musico-
} terapeuta. 
hace uso de uno de los instrumentos del setting. Tras la música, se entrega una hoja para que puedan plasmar cómo se han sentido durante la sesión o cómo se sienten en ese momento, pudiendo utilizar una frase, una palabra o un dibujo. Cada uno de ellos tiene un mensaje:

S5: “... con vergüenza de mí”.

S2: “... a gusto y feliz".

S3: “... luchar por los sueños".

S1: "... me siento libre como un pájaro".

S4: “... me gusta la música y mi vida depende a veces de ello".

Tercera Sesión: “Hasta cierto punto, la música ya no es mía, es tuya"

El grupo entra en sesión y se les pregunta cómo ha ido la semana. Cada uno de ellos cuenta su semana, pero el grupo se centra en S2, que está muy triste. La musicoterapeuta propone trasladar a lo musical lo que ha verbalizado S2.

S3: “... yo creo que es mejor que no hagamos música de eso, porque te vas a poner peor y vas a estar jodido".

S2: “... ya, pero me apetece hacerlo”.

Durante la improvisación, que dura aproximadamente 8 minutos, hay muchas miradas entre ellos. $S_{1}$ toca el piano, S2 la guitarra, S3 el djembe, $\mathrm{S}_{4}$ y $\mathrm{S}_{5}$ no tocan, están en silencio. La terapeuta musical toca el pandero. El silencio de $\mathrm{S}_{4}$ y S5 está presente en la improvisación de tempo tranquilo y con predominio melódico. Buscan cierta conexión entre ellos y la música representa cómo el grupo va tomando decisiones, por ejemplo, el final conjunto de la obra. Además, esta conexión se representa también con un largo silencio al final de la improvisación, que es interrumpido por uno de ellos:

S4: “¡Buah!, ¡Qué pasada! ¡Qué bonito!”. S3: “Cómo estás?” [le pregunta a S2].

S2: “... bien, me ha gustado mucho... no pensaba que pudiese llorar”.

Antes de terminar la sesión, S1, de manera voluntaria, trae preparada una canción de su historia sonora, "Yo te extrañaré" (Tercer Cielo, 2008), y plantea compartirla y escucharla con los compañeros. Durante la escucha, el grupo se muestra unido, se miran y buscan el contacto físico a modo de abrazo. $\mathrm{S}_{1}, \mathrm{~S}_{2}$ y $\mathrm{S}_{4}$ se emocionan. Por último, al igual que en la primera sesión, se propone trasladar al papel, a través del dibujo o de una palabra, lo que les ha evocado la escucha. La musicoterapeuta despide el encuentro recordando la canción de la primera sesión con la guitarra, a lo que el grupo acompaña cantando.
PERIOdo de TERAPIA. “LAS HERIDAS GRITAN" (SESIONES 7-17)

A lo largo de este periodo, la música que surge del grupo comienza a ser sincronizada, es decir, empiezan a trabajar poco a poco en equipo. En esta fase todo el grupo acude a las sesiones, excepto en la

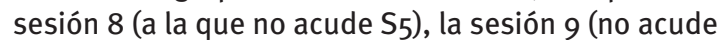
S4), la sesión 10 (no acude S1), la sesión 12 (no acude S4) y la 16 (no acude $\mathrm{S}_{5}$ ). Es decir, de once sesiones que agrupan esta segunda fase, en seis están todos y en las otras cinco restantes falta un integrante del grupo. Las sesiones que destacamos de esta fase son la 9,12 y 16 .

Novena sesión: “La música cuenta lo que guardan mis palabras"

Tras el saludo inicial, los participantes cogen los instrumentos y comienzan a tocar. Están todos menos S4. La terapeuta musical hace lo mismo y da comienzo una improvisación que tiene una duración de 21 minutos. S1 y S2 tocan el piano, S2 usa también las maracas y casi al final el djembe. S3 toca su trompeta y más tarde el triángulo. S5 no toca y la musicoterapeuta utiliza el djembe y después la guitarra. S5 se muestra cabizbajo y mira al suelo en silencio a lo largo de la creación. La terapeuta musical dirige la improvisación hacia una música que refleja el estado emocional de $\mathrm{S}_{5}$. Se sienta a su lado y con la guitarra comienza a reflejarlo musicalmente. El grupo, de manera no verbal, a través de las miradas, capta la intención y se une para reflejar a S5. Es música en la que predomina lo melódicoarmónico frente a lo rítmico, en una envoltura en modo menor, con un tempo tranquilo y con una conexión entre el grupo que se manifiesta a través de las miradas, imitaciones, diálogos musicales y en la finalización conjunta de la obra. Tras esta improvisación se hace un silencio con una duración de 35 segundos. A continuación, S2 llama por su nombre a $S_{5}$ interesándose por ver cómo está. Las intervenciones verbales después de la improvisación son tranquilas, se escuchan entre ellos y su tono de voz es relajado.

S2: “... a mí se me han quedado ganas de más...”. S1: “... a mí también”.

S3 propone expresar de manera individual y a través de la música cómo se sienten. Este empieza a improvisar con la trompeta y, después, habla sobre una decisión que tiene que tomar con respecto a su familia. Se abre un debate en el que se escuchan atentamente unos a otros. S1 y S2 deciden hacer la improvisación de manera conjunta. S1 en el piano y $\mathbf{S} 2$ en la guitarra, sentados juntos. S5 no quiere tocar instrumentos, prefiere escuchar. La musicoterapeuta propone una dinámica de improvisación para sostener a $S_{5}$ y anima a este a que se una al grupo si le apetece. Le parece bien la propuesta. La dinámica consiste en que $\mathrm{S}_{5}$ se coloca en el centro de un círculo, con los ojos cerrados y 
rodeado de sus compañeros. Se le pregunta a S5 qué le apetece escuchar, y responde que algo tranquilo. La improvisación grupal tiene una duración de 5 minutos y 49 segundos con una música íntima y muy conectada. Predomina lo melódico-armónico y se producen diálogos musicales entre los miembros del grupo. S1 toca el piano junto con la terapeuta. Esta toca en el registro grave y $\mathrm{S}_{1}$ en el agudo. S2 usa la guitarra. S3 en esta ocasión permanece en silencio junto con $\mathrm{S}_{5}$.

Duodécima sesión: “Cuando la música te alcanza, no sientes dolor"

El grupo entra en sesión y están todos menos S4. Resulta una sesión muy musical, con un total de cuatro improvisaciones. La primera tiene una duración de 5 minutos. A lo largo de la improvisación se producen varios cambios de instrumentos por parte del grupo, excepto $S_{3}$, que no toca ningún instrumento y se mantiene en silencio. La música en esta primera creación tiene predominio rítmico, de tempo agitado, no está del todo conectada, algunos hablan por encima de la música.

En la segunda improvisación, de 4 minutos y 40 segundos, se comienza de manera desorganizada, poco a poco se sincronizan y tocan más conectados. Es una música con predominio melódico y de tempo tranquilo al principio, que modula a una música más rítmica y de tempo más animado. En este caso S1 toca el djembe, S2 el piano, S3 de nuevo no toca y 55 usa el piano y las sonajas. Por último, la musicoterapeuta utiliza la guitarra y el djembe. Tras la música cuentan individualmente cómo están. S3 no quiere hablar, a pesar de que normalmente se muestra muy participativo.

Comienza una tercera improvisación de 14 minutos y 44 segundos, muy rítmica, conectada y de tempo agitado. Al ser una creación muy rítmica, en ocasiones se desordena ligeramente cuando se introduce un nuevo motivo rítmico, pero después se conecta. Hay alegría, S1 toca el piano, S2 utiliza el djembe, $S_{3}$ toca la trompeta y el djembe; $S_{5}$, que no suele utilizar instrumentos, toca el djembe, el triángulo, la pandereta y hace percusión corporal con palmas. La musicoterapeuta utiliza la guitarra y el djembe. En un momento dado, $\mathrm{S}_{5}$ se pone a bailar mientras toca las sonajas y S2 le acompaña en el movimiento.

Al terminar la improvisación se muestran enérgicos y contentos. S1 pide tocar "Hallelujah" (Cohen, 1984), canción que había traído S2 la semana anterior. Se toca la canción y se enlaza una última improvisación con una duración de 10 minutos en la que S1 toca el tonal que oscila entre el modo mayor y el menor y en la que el grupo va moviéndose conjuntamente por diferentes dinámicas desde piano hasta forte. Después, S3 trae preparada una canción de su historia sonora y se escucha en grupo - “Ahora lloras tu” (Mena, ft. CNCO, 2017)-. Bailan la canción de manera conjunta, comentan la coreografía que han hecho y bromean entre ellos. A continuación, realizan entre todos la reflexión sobre la letra.

Para cerrar la sesión, S3 quiere hacer una improvisación para S1. Cada uno de los miembros del grupo confirma que $\mathrm{S}_{1}$ ha recibido esta semana una desafortunada noticia, ya que va a ser trasladado a otro centro dentro de unos meses. S1 ha solicitado poder participar en todas las sesiones que faltan antes de marcharse. S3 utiliza la trompeta y es escuchado atentamente por el grupo.

\section{Decimosexta sesión: “Me gusta que las melodías bonitas me cuenten cosas terribles"}

El grupo se acomoda en la sala. $\mathrm{S}_{5}$ no ha venido y tras hablar unos minutos da comienzo una improvisación ordenada con textura melódico-rítmica y de un tempo que varía desde lento hasta agitado con una duración de diez minutos. Al terminar, el grupo cuenta el porqué de la ausencia de S5, ya que al parecer ha tenido un mal comportamiento y ha causado desperfectos en el hogar de acogida. Parece que va a estar un tiempo sin venir. El grupo se siente molesto con $\mathrm{S}_{5}$ por su comportamiento y así lo manifiestan en la sesión. Se expresan de manera ordenada y se apoyan los unos a los otros.

En la sesión anterior la musicoterapeuta propuso al grupo realizar un songwriting con frases recogidas en esa sesión. En forma de círculo en el suelo y haciendo un repaso de las frases sucede lo siguiente:

S3 [rapea mientras va leyendo]: “Érase una vez, un grupo de menores a los que les gustaba todos los días hacerse los cabrones, llegamos... y nos hicimos mejores, hasta que flotamos todas nuestras emociones, allí nos conocemos y aprendimos a llorar, que la música nos ayuda a relajarnos, a expresarnos... y sobre todo nos valoramos, cada uno de nosotros somos especiales y en los momentos malos nos ayudamos...".

Continúa la dinámica, y el grupo decide utilizar para el songwriting la melodía de "Hallelujah" cambiándole la letra. Se le da el título de "Los supervivientes". A lo largo de la composición van contando sus vivencias de la infancia. Se escuchan y se apoyan.

S2: [cuenta episodios duros de su infancia]. S3: " $i$ Tío, eres un superhéroe... tú eres un puto superhéroe y ya está!”.

S1 y S4: [señalan la edad a partir de la cual se empezaron a sentir queridos y relatan cómo era 
su vida hasta entonces].

S3: “... nunca entendí por qué me hicieron esas cosas... nunca lo supe...” [describe vivencias muy duras].

S4: “... somos como las estrellas del cielo, no necesitamos a nadie, brillamos con luz propia. Los educadores nos echan muchas veces un cable, aunque nos enfademos con ellos... siempre nos querrán, lucharán, nos apoyarán y nunca nos olvidarán...”.

S3: "Estarán siempre orgullosos de nosotros y de nuestro proceso...".

MTA: [informa al grupo de que la semana siguiente seguirán con la creación, puesto que solo quedan diez minutos de sesión]. S4: "Chicos, trabajamos superbién nosotros sin que esté $\mathrm{S}_{5}$, que se pone a decir chorradas...". S3: "Ya te digo...". S2: "iSí!".

Tras este trabajo, $\$ 4$ trae una canción de su historia sonora, "Veneno" (Nieto, 2014), y es analizada brevemente tras la escucha. Para la despedida, se realiza una improvisación que recoge lo evocado en la sesión. Tiene una duración de 7 minutos y 17 segundos, y en ella S1 utiliza el djembe, S2 toca el piano y hace percusión corporal, S3 toca la guitarra, $\mathrm{S}_{4}$ el djembe y percusión corporal y la musicoterapeuta acompaña con el piano y posteriormente con el djembe. La música, en la primera parte tiene un predominio rítmico y resulta desordenada; poco a poco se va sincronizando y modulando hacia una textura con predominio melódico. La musicoterapeuta va introduciendo los acordes y giros melódicos de la canción "Hallelujah", que es acompañada por el grupo cantando y tocando. Se despide la sesión cantando.

\section{CierRe Del PROCESO: "Colocando las DesPedidas" (SESIONES 18-20)}

Se aproxima el final del proceso terapéutico, pero el grupo tiene que hacer frente a otra despedida importante, ya que uno de los miembros va a ser trasladado a otro centro residencial fuera de la comunidad autónoma una vez finalice este proceso. El objetivo para esta fase es terminar el songwriting de "Hallelujah" que se comenzó a realizar a partir de la sesión 15, para que puedan llevarse una canción propia y poder así conservarla. En esta última fase, $\mathrm{S}_{5}$ falta a la sesión 18 y 19, y en la sesión 20 no acuden S2 y S4. La sesión relevante en esta fase es la 19.

\section{Decimonovena sesión: “La música es un eco del mundo invisible"}

A lo largo de esta penúltima sesión del proceso el grupo está muy revolucionado, hablan todos a la vez. Se producen diferentes conversaciones cruzadas. Vuelve el desorden, pero cuentan de manera individual cómo ha ido la semana. A pesar de estas interferencias, el grupo conecta y comienza una improvisación grupal con una duración de 6 minutos y 36 segundos, en la que $S_{1}$ toca el djembe, S2 el piano y la voz, S3 no toca, S4 utiliza el djembe y la musicoterapeuta la guitarra y la voz. Están muy sincronizados.

La música se organiza alrededor de una melodía en el piano a la que se añaden otros instrumentos armónicos como la guitarra y también rítmicos como el djembe. Se producen diferentes dinámicas en la música, que reflejan la conexión de los miembros del grupo con lo que se está haciendo. Se produce un decrescendo que deriva en un silencio para luego, poco a poco a través de un crescendo, volver al tema del que se había partido. Tras la improvisación, surgen las siguientes ideas (sin ser la última sesión, el grupo se está despidiendo):

S2: "La música ayuda a relajarse... yo en el momento de hacer música, me siento bien, pero luego cuando te vas, me vuelvo a sentir como una mierda...".

S1: “... a mí la música me ayuda cuando estoy mal... hace que me sienta bien...".

S3: “... yo creo que la música me ha ayudado...”. S4: “... la música me ayuda cuando estoy mal y no cuando estoy bien... la música que me alegra, malo, y la que me hace llorar, malo también, porque llorar es de débiles... a mí me ha ayudado a reflexionar porque luego lloras...".

Para finalizar la sesión, se abre una conversación sobre el songwriting que se iba a realizar y se decide dejarlo en el punto en el que se quedó. El grupo no consigue llevarlo a lo musical. Cada uno de ellos se lleva escritas las palabras y frases que surgieron.

\section{Evaluación y resultados}

El grupo de adolescentes, a pesar de conocerse entre sí y residir en un mismo hogar de acogida, rompen "simbólicamente" en cada sesión sus relaciones de confianza y amistad, especialmente en la fase de inicio y cierre. Se acusan, se insultan, se rechazan y desvelan secretos, que lanzan entre sí a modo de ataque delante del grupo. Un escenario con discusiones, desconfianza, interrupciones, llamadas de atención y alteración conductual, relacional y comunicativa. Cada miembro del grupo ensaya funcionamientos automáticos de desvinculación y desorganización. Un sistema de defensa ante lo desconocido, es decir, ante la figura de la terapeuta, el espacio terapéutico, la actividad y ante cada uno de sus compañeros de grupo desde lo musical. El grupo de adolescentes necesita más tiempo para confiar, calmarse y regularse entre ellos y hacia la musicoterapeuta. Estos modos relacionales en forma de bucle recurrente desconfiar-poner a prueba-confiar pueden ser un reflejo de aprendizaje, supervivencia y adaptación de su vida cotidiana y, por tanto, nuestro campo de estudio.

El grupo responde a la propuesta experimental con una asistencia significativa; no ha habido ningún 
abandono y las incidencias ocurridas responden a las características del colectivo en el transcurso previsible del trabajo terapéutico (Shaw, 1983; Rosas, 2001). La cohesión grupal guarda relación con la asistencia grupal por sesión y el aumento de la participación del grupo en ellas (Yalom y Leszcz, 2005). La experiencia confiable de tocar instrumentos les motiva, les atrae el setting y la exploración de estos. Durante la fase de terapia, a medida que el grupo se acomoda a la estructura de las sesiones, utilizan diferentes instrumentos y experimentan de manera individual y colectiva. La satisfacción del grupo se traduce en la producción y duración de las diferentes improvisaciones grupales a nivel musical. El hecho de que una improvisación se alargue en el tiempo muestra cómo consigue que se trabaje conjuntamente.

Sin embargo, las primeras improvisaciones musicales clínicas durante las seis sesiones iniciales se muestran fragmentadas y la música de cada uno de ellos no se conecta, puesto que existen interferencias verbales y bajo nivel de escucha. En general, hay poca conciencia de la música del otro, haciendo muy complicado el trabajo conjunto sobre un patrón rítmico común, que les encamine a la conexión y que da lugar a que cada miembro del grupo termine la improvisación en momentos diferentes. Entran en juego la representación de uno mismo y la del otro, es decir, cómo entienden las relaciones con los demás y cómo se ven ellos mismos, especialmente en las dificultades que presentan a la hora de trabajar y tomar decisiones en grupo.

Con un total de 30 ejecuciones musicales espontáneas, se observa el desarrollo y el comportamiento de la técnica de la improvisación musical en el grupo. Las improvisaciones, el número y la duración de estas aumentan de manera progresiva en el periodo de terapia (sesiones 7-17), siendo más largas y duraderas que en la fase de valoración (sesiones 1-6) y cierre (sesiones 18-20). En concreto, de la sesión número 6 a la primera sesión registrada del período de terapia (la sesión número 8 , ya que la 7 no se pudo registrar por problemas técnicos), existe una diferencia en aumento de la duración de la improvisación musical de más de 17 minutos. La ejecución musical grupal espontánea aumenta tímidamente con altibajos en la fase inicial de valoración para posteriormente recrearse en el período de terapia. Parece que, ante improvisaciones musicales más duraderas, el grupo aumenta en seguridad para explorar desde lo musical.

Sin embargo, no se comporta siempre hacia adelante y en aumento, ya que existen "dientes de sierra" y bloqueos, como en las sesiones 10 y 13 con improvisaciones que no superan los cinco

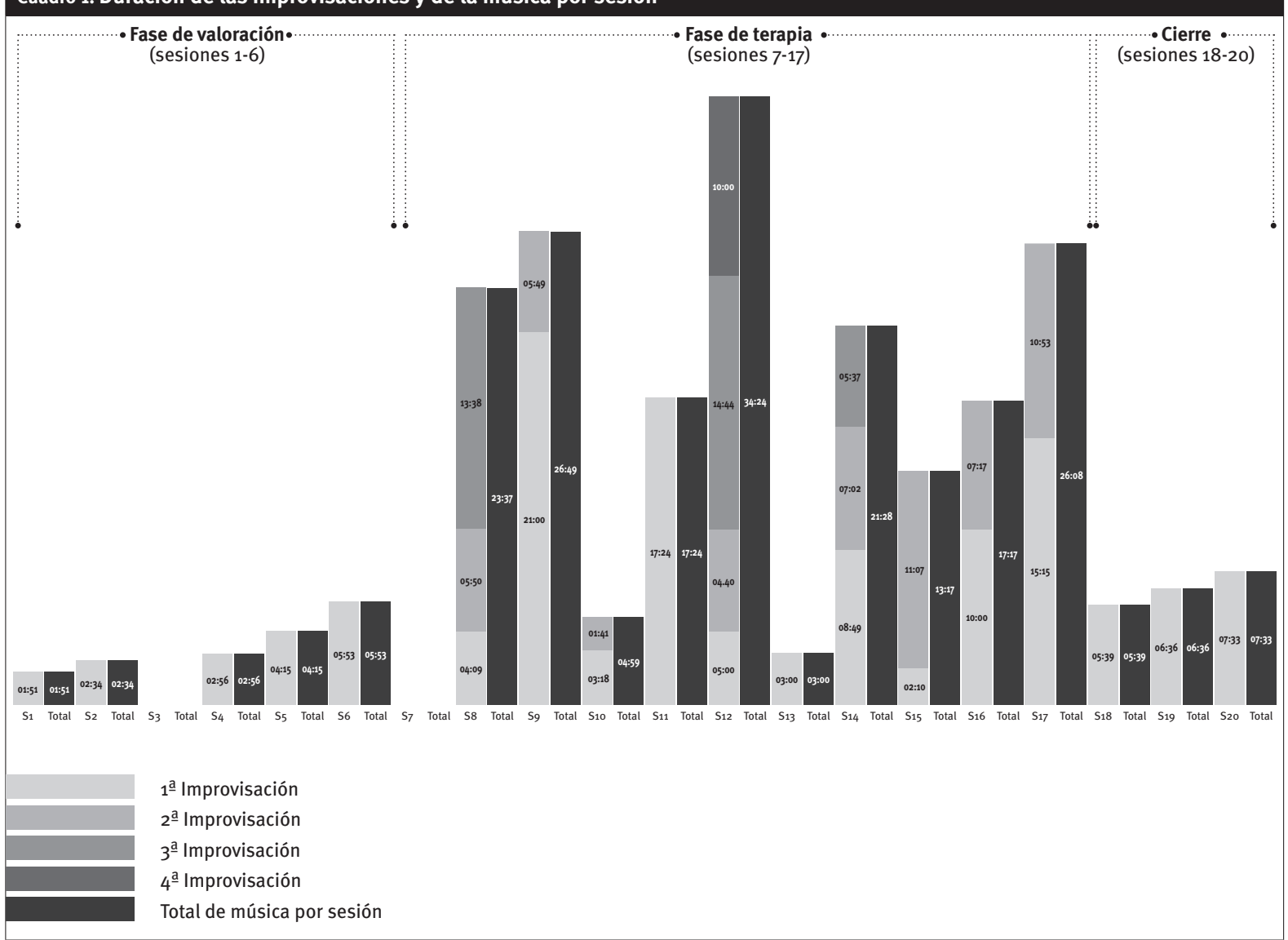

Fuente: Elaboración propia. 
minutos, es decir, idas y vueltas o estrategias de adaptación y defensa para mantener el control sobre ellos mismos (Berástegui, 2005). En esta línea de contrastes, hay dos miembros del grupo que presentan una participación menor en la ejecución instrumental de un número de sesiones, en favor de una mayor presencia silenciosa y escucha. Se han podido observar momentos de “congelación o hipoactivación” ante determinadas sesiones musicales y de "hiperactivación” tocando y alternando instrumentos musicales junto con movimientos a través del cuerpo, silbidos, palmas y bailes.

Sobre la duración media de las improvisaciones musicales y su producción, desde la fase de valoración al periodo de terapia, se produce una diferencia en positivo de 15 minutos y 21 segundos, mientras que del periodo de terapia al cierre, la diferencia resulta negativa en 12 minutos y 14 segundos. En términos porcentuales, en más de la mitad de las sesiones hubo una improvisación, en el $25 \%$, dos y en el $15 \%$, tres o más. Este contraste entre la fase de valoración y la del periodo de terapia puede deberse al propio carácter experimental, indirecto y novedoso de la actividad y de la propia técnica en sus diversas aplicaciones con un fin preciso. La presencia de estos picos tan acentuados en la duración media de las improvisaciones puede asociarse a una tendencia previsible en la población adolescente con apego desorganizado, bien con adolescentes más evitativos donde se minimiza la emocionalidad y se maximiza la independencia, bien con estilos de relación que pueden oscilar bruscamente entre el acercamiento desconfiado y la repentina retirada con gran intensidad (Barudy y Dantagnan, 2005). Puede ocurrir también que, dentro de un entorno de seguridad, los miembros del grupo tomen decisiones musicales más arriesgadas, que pueden cuestionar y tambalear la conexión musical (Beth, 2012).

Cuadro 2. Duración total y media de las improvisaciones grupales por fase 4

\begin{tabular}{|l|c|c|}
\hline Periodo & Duración total & Duración media \\
\hline $\begin{array}{l}\text { Fase de valoración } \\
\text { (sesiones 1-6) }\end{array}$ & $\begin{array}{c}17 \text { minutos } \\
29 \text { segundos }\end{array}$ & $\begin{array}{c}3 \text { minutos } \\
29 \text { segundos }\end{array}$ \\
\hline $\begin{array}{l}\text { Periodo de terapia } \\
\text { (sesiones 7-17) }\end{array}$ & $\begin{array}{c}3 \text { horas } 8 \text { minutos } \\
23 \text { segundos }\end{array}$ & $\begin{array}{c}18 \text { minutos } \\
50 \text { segundos }\end{array}$ \\
\hline $\begin{array}{l}\text { Cierre } \\
\text { (sesiones 18-20) }\end{array}$ & $\begin{array}{c}19 \text { minutos } \\
48 \text { segundos }\end{array}$ & $\begin{array}{c}6 \text { minutos } \\
36 \text { segundos }\end{array}$ \\
\hline
\end{tabular}

Fuente: Elaboración propia.

El paso de improvisaciones más cortas hacia más duraderas en la fase de terapia podría ser resultado de que el grupo ha pasado de la sobreadaptación inicial desde la individualidad a la validación como grupo emocional. En este sentido, cuando dos o más

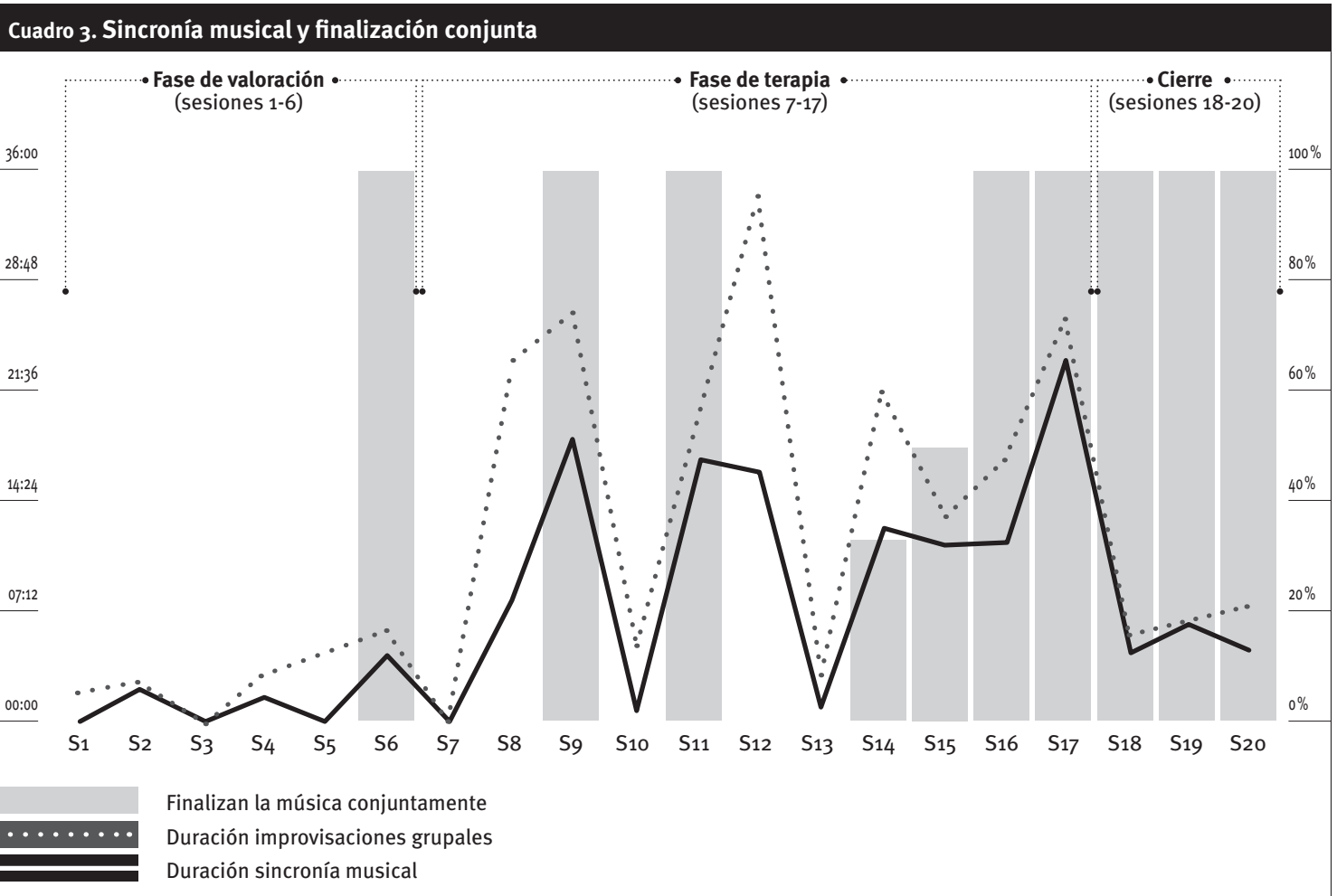

Fuente: Elaboración propia. 
personas tocan juntas, tienden a alinearse y a unirse, provocando una mayor conexión de los estados físicos y de las emociones del otro (Rabinowitch, Cross y Burnard, 2012). Es decir, diferentes ensayos de presintonización emocional donde el grupo funciona dentro de las pautas y reglas que se acomodan para este espacio y se familiariza con la dinámica de cada sesión, no interrumpiendo la música verbalmente y tampoco cuando alguien habla. Se estimula el respeto y se evitan los comentarios ofensivos, promoviendo el protagonismo individual dentro del grupo de manera operativamente activa y en forma de satisfacción por hacer música juntos, favorecer la conexión, la duración y la producción. De ahí que tanto la improvisación instrumental grupal como la concurrencia de sonidos, movimientos 0 acciones nos aproxima al fenómeno de la sincronía musical y de la cohesión grupal (Fernández, 2011).

En este sentido, la figura de la musicoterapeuta analiza el conjunto de las producciones musicales espontáneas y considera que existe sincronía musical cuando la pulsación musical es común en los miembros del grupo y cuando el tempo, las dinámicas y texturas de la música son similares, incluyendo la finalización conjunta de la música. Así pues, parece que cuando el grupo se encuentra en sincronía musical, los adolescentes conectan con la música, con ellos mismos y con los demás, favoreciendo la cohesión grupal versus individualidad o herida narcisista. La sincronía musical a lo largo de esta intervención ha ido en aumento, aunque se comporta de manera desigual por sesión. De hecho, da sus primeros pasos tímidamente en la fase de valoración, destacando especialmente en la sesión 6. Estos contrastes acentuados y bruscos en cuanto a presencia y ausencia de sincronía persisten en las siguientes seis sesiones, aumentando y disminuyendo cada tres sesiones. En este sentido, se produce un asentamiento en las últimas sesiones del periodo de terapia y cierre, en el que la duración entre la improvisación musical grupal y la sincronía musical pasan a estar muy conectadas, especialmente en la sesión 17, en la que sucede el punto más alto de la sincronía musical grupal y la duración de la improvisación.

A medida que aumenta en minutos la duración de las improvisaciones, la sincronía musical no se solapa ni se comporta del mismo modo. De hecho, el porcentaje de sincronía total por periodo resulta superior en la fase de cierre con un 79,04\% que el resto de fases. Probablemente la sincronía musical pueda estar vinculada a múltiples factores, como el clima emocional por el que transita el individuogrupo-terapeuta, el tiempo y la experimentación en la improvisación a través de diferentes sesiones en las que prevalece lo previsible y la armonía relacional versus las pruebas iniciales, dificultades y rechazos individuales. En este sentido, el desarrollo de la sincronía se puede asociar también a cómo cada miembro del grupo va conociendo desde lo musical a cada uno de sus compañeros, haciendo más sencillo conectarse entre sí puesto que pueden predecir el "estilo" musical de cada uno de ellos. Esto sucede ya que cada individuo no está únicamente centrado en lo que él hace, sino que es capaz de escuchar, predecir y empatizar con lo que hacen sus compañeros, revelando que el grupo tiene el propósito común de realizar una improvisación grupal "entre" todos y no "con" todos, mostrando que son capaces de trabajar en equipo, de ir cediendo en los protagonismos individuales de cada uno de ellos y resolver los conflictos que puedan ir surgiendo a lo largo de la obra.

De hecho, en aquellas sesiones donde aumenta la producción de improvisaciones musicales no necesariamente aumenta la sincronía musical. Ahora bien, las sesiones en las que aumenta la sincronía musical se caracterizan por pertenecer al final de la fase de terapia y por improvisaciones musicales más estructuradas informalmente y con una duración más larga. Esto les ayuda a ensayar y a entrar en lo musical, adaptándose a los otros y permitiendo la finalización grupal conjunta de la música. En resumen, parece que se puede hablar de ensayos de presintonización emocional y prementalización a través de aquellas improvisaciones musicales en las que el grupo conecta, se sintoniza y transita más allá de lo musical, promoviendo la cooperación y la solidaridad y reforzando la interacción grupal (Amodeo, 2014).

\section{Conclusiones}

Más allá de la urgencia por conseguir cambios en el funcionamiento familiar o en el abordaje de los problemas de conducta, se han favorecido condiciones de espacio transicional y tiempos suficientemente estables para el encuentro con el otro. Un espacio intermedio de intercambio que

Cuadro 4. Duración y porcentaje de la sincronía por fase

\begin{tabular}{|l|c|c|c|}
\hline Periodo & $\begin{array}{c}\text { Duración total de la música por } \\
\text { fase }\end{array}$ & $\begin{array}{c}\text { Duración total de la sincronía por } \\
\text { fase }\end{array}$ & $\begin{array}{c}\text { Porcentaje de sincronía total por } \\
\text { fase }\end{array}$ \\
\hline $\begin{array}{l}\text { Fase de valoración } \\
\text { (sesiones 1-6) }\end{array}$ & 17 minutos 29 segundos & 8 minutos 27 segundos & $48,33 \%$ \\
\hline $\begin{array}{l}\text { Período de terapia } \\
\text { (sesiones 7-17) }\end{array}$ & 3 horas 8 minutos 23 segundos & 2 horas 20 segundos & $63,88 \%$ \\
\hline $\begin{array}{l}\text { Cierre } \\
\text { (sesiones 18-20) }\end{array}$ & 19 minutos 48 segundos & 15 minutos 39 segundos & $79,04 \%$ \\
\hline
\end{tabular}

Fuente: Elaboración propia. 
ha buscado, a través del objetivo de la cohesión grupal, estimular aspectos propios y de los demás (Winnicott, 1959; 1970; Ariz, 2016). En resumen, un planteamiento creativo de terapia con música en un tercer espacio de diversos modos. Un tránsito experimental de la regulación interpersonal a la intrapersonal, especialmente, como complemento a la terapia tradicional en destinatarios con trauma infantil en el contexto de las relaciones de apego, trauma interpersonal temprano o con síntomas de disociación infantil y adolescente (Marrone, 2001; Silberg, 2019).

Con todo ello, la musicoterapia y la técnica de la improvisación musical clínica pueden resultar instrumentos válidos de aproximación a colectivos que presentan dificultades en la capacidad de simbolización y mentalización, que les impiden implicarse y "hacer suyo" un proceso terapéutico. En este sentido, el aumento de un cuerpo de investigaciones en esta realidad académica y profesional, que avanza lentamente en el reconocimiento científico, permitiría generalizar las ventajas o las dificultades de su implementación como apoyo, alternativa e innovación a los tratamientos habituales y su inclusión en los contextos específicos de acogida de menores, protección específica de adolescentes o menores infractores. No obstante, el carácter exploratorio de esta propuesta necesitaría de un consenso metodológico, validado en torno a la producción de la improvisación musical y a la medición de esta, con relación a la cohesión de grupo y a la sincronía (Hakes, 1996; Beth, 2012). No menos importante es la cuestión de analizar y valorar previamente y con detenimiento, al destinatario de la intervención en concreto de cara a un encuadre acertado sobre una determinada corriente o modalidad de intervención terapéutica individual o grupal (Oslé, 2011; Briones, Rajcic y Gamella, 2017).

En cuanto al objeto de estudio, el grupo consigue desarrollar en el $60 \%$ de las sesiones, improvisaciones grupales musicales de manera cohesionada y alcanzar más de un $70 \%$ de sincronía musical en aquellas ejecuciones espontáneas surgidas a lo largo de las últimas sesiones del periodo de terapia y cierre. Sin embargo, la clave del proceso radica en que el grupo necesita más de un $25 \%$ de las sesiones, especialmente en la fase de inicio y en algunas sesiones intermedias, para conseguir adaptarse y confiar. Más que los resultados finales, la aportación significativa de esta propuesta se encuentra en la exposición y ensayo a modo de ejercicios para presintonizar con los estados físicos y emocionales de los otros. Todo ello proporciona apoyo, estabilidad y seguridad hacia el autoconocimiento de cada miembro del grupo, facilitando oportunidades de expresión, aceptación e identificación (Malbrán, 2007; Bruscia, 2010; Fernández, 2011; Rabinowich, Cross y Burnard, 2012). Sobre la labor técnica de la musicoterapeuta, resultan aspectos complejos la escucha, la espera y el entendimiento al grupo y a cada uno de sus miembros desde el contexto no verbal, sin olvidar la preparación, desarrollo y cierre de las sesiones junto con el posterior análisis de los resultados (Benenzon, 1998).

En la disposición del nivel de implicación de cada adolescente con relación al grupo, al espacio y al trabajo terapéutico, la musicoterapeuta recoge a través de las diferentes narrativas y el diario de sesiones diferentes observaciones en los siguientes ámbitos de intervención (Del Barrio, Sabbatella y Brotons, 2018; 2019): con relación al ámbito motor, desde mediados de la intervención se reducen los momentos de impulsividad, brusquedad e inactividad en cada individuo en favor de una mayor conciencia corporal y postural respecto al grupo y al espacio terapéutico durante las sesiones, así como a la entrada y salida de la sala. Ahora bien, tanto en la fase de inicio como en la fase final se han producido patrones reactivos de comportamiento impulsivo, siendo en la etapa de cierre de menor intensidad que en la de inicio.

Con relación al ámbito emocional, la terapeuta musical recoge cómo los miembros del grupo observan los sentimientos de los otros, entrenan situaciones de presintonización emocional, autoobservan las propias emociones y llegan a poder verbalizar frases y algunas impresiones sobre situaciones difíciles vividas a lo largo de su infancia (North, Hargreaves y O’Neill, 2000; McFerran, 2010). En el ámbito cognitivo, los miembros del grupo consiguen finalizar la música de manera conjunta, intercambian instrumentos musicales, trabajan la atención, la escucha y la confianza.

En el ámbito comunicativo (Amir, 2004; Andrade, 2005), respetan el turno de improvisación musical y de palabra tanto cuando se expresan de manera individual como a través de la improvisación grupal. También aceptan instantes de naturaleza no verbal de la música y recogen las propuestas musicales de los otros. Se miran a los ojos al hablar y manifiestan preocupación. Sobresale cómo superan la perspectiva "psicologizada" en cuanto al proceso de intervención, ya que algunos adolescentes presentan repertorios automatizados de clínica tradicional, reproduciendo términos profesionales en sus respuestas durante algunas sesiones delante del grupo. Por último, y con respecto al ámbito social (Cross, 2009), comparten un propósito común, se comportan de manera adecuada en el espacio terapéutico, mantienen la asistencia, participación y adaptación a las normas del grupo y preservación frente a las interferencias externas, como malas noticias o episodios de alteraciones conductuales graves sucedidas en el centro de acogida, en la escuela, con amistades o con la familia.

Son varias las limitaciones de este estudio experimental. Por un lado, el proceso de intervención en sí mismo, ya que se trata de una propuesta específica de terapia musical en un contexto concreto como es la acogida residencial de adolescentes 
con experiencias de acogimientos interrumpidos en la adopción. Por otro lado, este estudio de aproximación necesita una muestra amplia, validada y contrastada como para poder llegar a generalizar posibles resultados, avances y beneficios en cuanto a intervenciones más globales, eficaces y positivas. Sobre el análisis e interpretación de los datos, sería recomendable observar los datos cuantitativos con la mayor sofisticación estadística posible, y sobre la información cualitativa, considerar no solo los casos afectados, sino también grupos de población general y de referencia. La investigación en musicoterapia no siempre resulta lo suficientemente precisa respecto a la metodología de análisis de datos. Las conclusiones de las investigaciones deben examinarse y compararse bajo el prisma de los métodos utilizados para avanzar en alcance y significación.

Con relación a posibles líneas de investigación futuras, nuevos estudios añadirán probablemente una mayor diversidad de propuestas experimentales y metodológicas dirigidas a diferentes colectivos, un análisis comparativo de las creaciones musicales improvisadas, incluso sobre el uso del setting o de los instrumentos musicales en las sesiones y el avance tecnológico e informático en las nuevas técnicas y metodologías aplicadas. 
AGINTZARI (2005): La postadopción en la Comunidad Autónoma del País Vasco. Claves para un abordaje estratégico del fenómeno de la postadopción, Bilbao, Agintzari.

AGINTZARI (2006): Guía de postadopción para profesionales de la educación y agentes sociales: claves educativas, Vitoria-Gasteiz, Servicio Central de Publicaciones del Gobierno Vasco.

AGINTZARI (2008): Guía para niños adoptados y niñas adoptadas, Vitoria-Gasteiz, Gobierno Vasco.

ALZATE, R. et al. (1997): “Análisis del impacto del estilo de comunicación del entrenador en el desarrollo de la cohesión grupal, la eficacia colectiva y la satisfacción", Revista de Psicología del Deporte, vol. 6, ํํ- 2 .

AMIR, D. (2004): “Giving trauma a voice: The role of improvisational music therapy in exposing, dealing with and healing a traumatic experience of sexual abuse", Music Therapy Perspectives, vol. 22, no 2, pp. 96-103, 〈https:// doi.org/10.1093/mtp/22.2.96>.

AMODEO, M.R. (2014): “Origen de la música como un rasgo adaptativo en el humano", Revista Argentina de Ciencias del Comportamiento, vol. 6, nํㅜ 1, pp. 49-59.

ARIZ, G. (2016): "Winnicott, espacio transicional entre el psicoanálisis relacional y la protección infantil”, Clínica e Investigación Relacional, Revista Electrónica de Psicoterapia, vol. 10, nํㅜ 1, pp. 222-239, <https//doi.org/10.21110/19882939. 2016.100115>.

ANSDELL, G. (1990): “Limitations and potential: A report on a music therapy group for clients referred from a counselling service", British Journal of Music Therapy, vol. 4, no 1, pp. 21-26, 〈https://doi.org /10.1177/135945759000400104〉.
ANDRADE, N. (2005): "La alianza terapéutica", Clínica y Salud, vol.16, n- 1, pp. 9-29.

ARNASON, C.L.R. (2002): "An eclectic approach to the analysis of improvisations in music therapy sessions", Music Therapy Perspectives, vol. 20, no 1, pp. 4-12. 〈https://doi.org/10.1093/ $\mathrm{mtp} / 20.1 .4$ '.

BRAVO, A. y FERNÁNDEZ DEL VALLE, J. (2001): “Evaluación de la integración social en acogimiento residencial”, Psicothema, vol. 13, nํㅡ, pp. 197-204.

BAKER, F. y WIGRAM, T. (2005): Songwriting. Methods, Techniques and Clinical Applications for Music Therapy Clinicians, Educators and Students, Londres, Jessica Kingsley Publishers.

BARUDY, J. y DANTAGNAN, M. (2005): Los buenos tratos a la infancia. Parentalidad, apego y resiliencia, Barcelona, Gedisa Editorial.

BARUDY, J. et al. (2014): La inteligencia maternal, Barcelona, Gedisa Editorial.

BENEDITO, M.C. (2010): “Reflexiones en torno a la utilidad de la música en la terapia psicológica con adolescentes", Revista Española de Pediatría, vol. 66, no 2, pp. 136-140.

BENENZON, R. (1998): La nueva musicoterapia, Buenos Aires, Lumen.

BERÁSTEGUI, A. (2003): Las adopciones internacionales truncadas y en riesgo en la Comunidad de Madrid, Madrid, Consejo Económico y Social de la Comunidad de Madrid.

BERÁSTEGUI, A. (2005): La adaptación familiar en adopción internacional: una muestra de adoptados mayores de tres años en la Comunidad de Madrid, Madrid, Consejo Económico y Social de la Comunidad de Madrid. 
BERÁSTEGUI, A. (2007): “Adopciones rotas: el peligro de un nuevo maltrato”, Revista Española de Pediatría, vol. 4, no 63, pp. 314-321.

BERÁSTEGUI, A. (2017): “El papel de los profesionales en la prevención de rupturas en adopción”, Revista Clínica Contemporánea, vol. 8, nํe14, pp. 1-10. 〈https://doi.org/10.5093/cc2017a7〉.

BERÁSTEGUI, A. (2018): "Variables en la definición de los fracasos en la adopción, variables en el éxito de las adopciones", en JEANNIN, C. (ed.), Fortaleciendo las competencias: aprender de los fracasos en la adopción internacional, Ginebra, Servicio Social Internacional.

BETH, E. (2012): Establishing an understanding of group dynamics and process within single-session music therapy groups open to both adolescents with mental illness and mental health staff [tesis de máster], New Zealand School of Music, <http://www.soundcooperation.nl/images/ stories/BandBuilding/groepsdynamiek/thesis. pdf〉.

BETTS, D.J. (2003): Creative Arts Therapies Approaches in Adoption and Foster Care: Contemporary Strategies for Working with Individuals and Families, Springfield, Charles C. Thomas Publisher.

BRIONES, I.; RAJCIC, M. y GAMELLA, D. (2017): "Musicoterapia con preadolescentes: los beneficios grupales de las sesiones individuales", Revista de Investigación en Musicoterapia, vol. 1, pp. 68-84.

BRODZINSKY, D. y SMITH, S. (2019): “Understanding research, policy and practice issues in adoption instability", Research on Social Work Practice, vol. 29, nํㅜ 2, pp. 185-194. 〈https://doi. org/10.1177/1049731518782647〉.

BRUSCIA, K. (1997): Definiendo musicoterapia, Salamanca, Amarú Ediciones.

BRUSCIA, K. (2010): Modelos de improvisación en musicoterapia, Vitoria-Gasteiz, AgrupArte.

CABRERA, M. (2007): “La calidad del acogimiento residencial desde la perspectiva de los menores", Infancia y Aprendizaje, vol. 30, nํㅜ 1, pp. $25-38$.

CAMPOS VIDAL, J.F. (2000): · Los factores terapéuticos: ¿qué es lo que produce cambios en los grupos?·, Alternativas. Cuadernos de Trabajo Social, no 8, pp. 205-229, 〈http://hdl.handle. net/10045/5757/.

CARUTH, C. (1996): Unclaimed Experience. Trauma, Narrative and History, Baltimore, The Johns Hopkins University Press.

CHEN, X. J. et al. (2014): “Group music therapy for prisioners: Protocol for a randomized controlled trial", Nordic Journal of Music Therapy, vol. 23, no 3, pp. 224-241, <https://doi.org/10.1080/o8 098131.2013 .854268 >.

COHEN, L. (1984): “Hallelujah” [producida por John Lissauer], en Various Postions, Columbia Records.

CROSS, I. (2009): "The nature of music and its evolution", en HALLAM, S., CROSS, I., \& THAUT, M. (eds.), The Oxford Handbook of Music Psychology, Oxford, Oxford University Press, pp. 3-13.
DEL BARRIO, L.; SABBATELLA, P.L. y BROTONS, M.M. (2019): "Musicoterapia en educación: Un proyecto de innovación orientado a la inclusión del alumnado con necesidades educativas especiales", Revista Música Hodie, <https:// doi.org/10.5216/mh.v19.51723>.

DÍAZ ATIENZA, J. y BLÁNQUEZ, M.P. (2004): “El vínculo y psicopatología en la infancia: evaluación y tratamiento", Revista de Psiquiatría y Psicología del Niño y del Adolescente, vol. 4, nํㅜ 1, pp. 82-90.

DÍAZ, K.; MARTÍNEZ, M. y REVELO, C. (2011): “La improvisación como medio para explorar patrones musicales de expresión en población infanto-adolescente abusada sexualmente", Unaciencia, vol. 4, nํㅜ 7, pp. 44-59.

EVAN B. DONALSON ADOPTION INSTITUTE (2004): What's Working for Children: A Policy Study of Adoption Stability and Termination, Nueva York, Evan B. Donalson Adoption Institute.

FERNÁNDEZ RIVAS, A. et al. (2013): “Adopción y alteraciones de conducta en la adolescencia. Estudio en población hospitalaria”, Anales de Pediatría, vol. $80, n^{-}$1, pp. 21-27, <https://dx.doi. org/10.1016/j.anpedi.2013.02.023〉.

FERNÁNDEZ-BATANERO, J.M. y CARDOSO, J.M. (2016): "Musicoterapia e integración social en menores infractores", Perfiles Educativos, vol. 38, nํ152, pp. $163-180$

FERNÁNDEZ-DAZA, M. y FERNÁNDEZ-PARRA, A. (2013): Problemas de comportamiento y competencias psicosociales en niños y adolescentes institucionalizados, Universitas Psychological, vol. 12, nº 3, pp. 797- 810, <https://doi. org/10.11144/Javeriana.upsy12-3.pccp〉.

FERNÁNDEZ-RASINES, P. y BOGINO, M. (2013): "Parentalidades cambiantes: entre la renuncia a la maternidad y la reivindicación de la custodia paterna", Grafo Working Papers, vol. 2, pp. 1-16. 〈https://doi.org/10.5565/rev/ grafowp.7〉.

FERRANDIS, A. (2017): "La reforma de la adopción cumple treinta años”, Revista Clínica Contemporánea, vol. 8, nํㅜ 2, e13, pp. 1-14. 〈https://doi. $\operatorname{org} / 10.5093 /$ cc2017a13〉.

GALÁN RODRÍGUEZ, A.G. (2014): “Tratamiento psicológico de niños y adolescentes en acogimiento residencial. Aportaciones a un campo específico de intervención", Papeles del Psicólogo, vol. 35, n 3, pp. 201-209.

GARAIGORDOBIL, M. (1998): Evaluación psicológica: bases teórico-metodológicas, situación actual y directrices de futuro, Salamanca, Amarú.

GARCÍA-CASARES, N.; MORENO-LEIVA, R.M. y GARCÍAARNÉS, J.A. (2017): “Efecto de la musicoterapia como terapia no farmacológica en la enfermedad de Alzheimer. Revisión sistemática", Revista de Neurología, vol. 65, no 12, pp. 529-538. 〈https://doi.org/10.33588/ rn.6512.2017181>.

GOLD, C.; VORACEK, M. y WIGRAM, T. (2004): “Effects of music therapy for children and adolescents with psychopathology: A meta-analysis", Journal of Child Psychology and Psychiatry, vol. 45, n으, , pp. 1054-1063, <https://doi. org/10.1111/j.1469-7610.2004.t01-1-00298.x〉. 
GONZALO MARRODÁN, J.L. (2010): “La relación terapéutica y el trabajo de reconstrucción de la historia de vida en el tratamiento psicoterapéutico de los niños crónicamente traumatizados", Cuadernos de Psiquiatría y Psicoterapia del Niño y del Adolescente, n- 49, pp. 187-204.

GONZALO MARRODÁN, J.L. (2015): Vincúlate. Relaciones reparadoras del vínculo en los niños adoptados y acogidos, Bilbao, Descleé de Brouwer.

GROCKE, D. y WIGRAM, T. (2008): Métodos receptivos en musicoterapia. Técnicas y aplicaciones clínicas para musicoterapeutas, educadores y estudiantes, Vitoria-Gasteiz, AgrupArte.

HAKES, R. (1996): Group cohesiveness represented through a multidimensional analysis of group improvisations [tesis de máster], Western Michigan University, 〈https://scholarworks. wmich.edu/masters_theses/636/>.

HILLER, J. (2009): "Use of and instruction in clinical improvisation", Music Therapy Perspectives, vol. $27, \mathrm{n}^{0}$ 1, pp. 25-32, 〈https://doi. org/10.1093/mtp/27.1.25 .

JANET, P. (1889): L'automatisme psychologique, París, Alcan.

JAUSET, J.A. (2014): Música y neurociencia: la musicoterapia, sus fundamentos, efectos y aplicaciones terapéuticas, Barcelona, UOC.

JEANNIN, C. (ed.). (2018): Fortaleciendo las competencias: aprender de los fracasos en la adopción internacional, Ginebra, Servicio Social Internacional.

KASER, V.A. (1993): “Musical expressions of subconscious feeling: A clinical perspective”, Music Therapy Perspectives, vol. 11, $\mathrm{n}$ 0 1, pp. 16-23, 〈https:// doi.org/10.1093/mtp/11.1.16>.

KERN, P. (2011): “Announcing WFMT's NEW Definition of Music Therapy", World Federation of Music Therapy, 〈https://www.wfmt.info/2011/05/01/ announcing-wfmts-new-definition-of-musictherapy/s.

LAYMAN, D.L.; HUSSEY, D.L. y LAING, S.J. (2002): “Music therapy assessment for severely emotionally disturbed children: A pilot study", Journal of Music Therapy, vol. 39, n- 3, pp. 164-187, 〈https://doi.org/10.1093/jmt/39.3.164'.

LECANNELIER, F. (2014): “Intervención y aplicaciones clínicas de la teoría del apego", en: TORRES GÓMEZ DE CÁDIZ, B.; CAUSADIAS, J.M. y POSADAS, G. (comps.): La teoría del apego: investigación y aplicaciones clínicas, Madrid, Psimática, pp. 205-226.

LEE, C. (2000): "A method of analyzing improvisations in music therapy", Journal of Music Therapy, vol. 27, no 2 , pp. 147-167, 〈https://doi.org/10.1093/ jmt/37.2.147>.

LIEBERMAN, A.F. y KNORR, K. (2007): "The impact of trauma: A development framework for infancy and early childhood", Psychiatric Annals, vol. 37, no 6, pp. 416-422, 〈https://doi.org/10.3928/0090-448120070401-10>.

LIMB, C. y BRAUN, A. (2008): "Neural substrates of spontaneous musical performance: an FMRI study of jazz improvisation", PLoS One, vol. 3, no 2, pp. 1-9, <https://doi.org/10.1371/journal. pone.0001679>.
LIONETTI, F.; PASTORE, M. y BARONE, L. (2015): “Attachment in institutionalized children: A review and meta-analysis", Child Abuse \& Neglect, vol. 42, pp. 135-145, <https://doi.org/10.1016/j. chiabu.2015.02.013〉.

LOIZAGA, F. (2009): Adopción internacional: ¿cómo evolucionan los niños, las niñas y sus familias?, Bilbao, Mensajero.

LÓPEZ SÁNCHEZ, F. (2015): “Adolescencia. Necesidades y problemas. Implicaciones para la intervención”, Adolescere. Revista de Formación Continuada de la Sociedad Española de Medicina de la Adolescencia, vol. 3, nํㅜ 2, pp. 9-17.

MALBRÁN, S. (2007): "Sincronía rítmica y tempo: Un estudio con adultos músicos", en III Reunión de la Sociedad Argentina para las Ciencias Cognitivas de la Música [actas], La Plata, Facultad de Bellas Artes (UNLP).

MARRONE, M. (2001): La teoría del apego. Un enfoque actual, Madrid, Psimática.

MATEOS-HERNÁNDEZ, L.A. (2011): Musicoterapia. Guías de implantación. Intervenciones no farmacológicas, Madrid, Imserso.

MCFERRAN-SKEWES, K. (2003): "Contemplating the nature of adolescent group improvisations", Voices: A World Forum for Music Therapy, vol. 3, nํㅜ 3, 〈https://doi.org/10.15845/voices.v3i3.133〉.

MCFERRAN, K. (2010): Adolescents, Music and Music Therapy: Methods and Techniques for Clinicians, Educators and Students, Londres, Jessica Kingsley Publishers.

MCFERRAN, K.; ROBERTS, M. y O'GRADY, L. (2010): Music therapy with bereaved teenagers: A mixed methods perspective, Death Studies, vol. 34, n- 6, pp. 541-565. 〈https://doi. org/10.1080/07481181003765428>.

MENA, A. ft. CNCO (2017): “Ahora lloras tú” [producido por Promusicae], en Index, WM Spain.

MONTÁNCHEZ, M. y ORELLANA, C. (2015): “Aprendizaje socioemocional en la adolescencia a través de la musicoterapia”, Iberoamérica Social: Revista-red de estudios Sociales, $\mathrm{n}^{-}{ }_{4}, \mathrm{pp}$. 164-174.

MORENO COUTIÑO, A. (2012): “Terapias cognitivoconductuales de tercera generación (TTG): la atención plena/mindfulness", Revista Internacional de Psicología, vol. 12, no 1, pp. 1-18, 〈https://doi.org/10.33670/18181023. v12i01.66).

MOSQUERA, C. (2013): "Influencia de la música en las emociones: una breve revisión”, Realitas. Revista de Ciencias Sociales, vol. 1, nำ 2, pp. 34-38.

NORTH, A.; HARGREAVES, D.J. y O'NEILL, S.A. (2000): "The importance of music to adolescents", British Journal of Educational Psychology, vol. 70, n- 2, pp. 255-272, 〈https://doi. org/10.1348/000709900158083>.

NIETO, I. (2014): "Veneno" [producido por Magic Beats], en Veneno, Grimey Music.

OSLÉ, R.O. (2011): “Musicoterapia y psicoterapia”, Advances in Relational Mental Health, vol. 10, pp. 1-9.

PADILLA, D. et al. (2017): “El tratamiento grupal de adolescentes con trastornos graves de la 
personalidad: una aproximación contextual", Revista de la Asociación Española de Neuropsiquiatría, vol., 37, nํ132, pp. 349-378.

PALACIOS, J. (2017): “Adopción no es patología”, Revista Clínica Contemporánea, vol. 8, nำ12, pp. 1-10, 〈https://doi.org/10.5093/cc2017a9〉.

PALACIOS, J. (2019): "When things do not go as expected: Adoption breakdown", The Future of Adoption, pp. 1-6.

PALACIOS, J. et al. (2018): “Adoption breakdown: Concept, research and implications", Research on Social Work Practice, vol. 29, nํㅡ, pp. 130-142, 〈https://doi.org/10.1177/1049731518783852〉.

PANIAGUA, C.; PALACIOS, J. y JIMÉNEZ-MORAGO, J.M. (2019): "Adoption breakdown and adolescence", Child and Family Social Work, vol. 24, nํㅜ 4, pp. 512518, 〈https://doi.org/10.1111/cfs.12631〉.

PARRA-RAMAJO, B. (2012): “Estudio sobre los factores de cambio en grupos socioeducativos de familias de acogida extensa", Portularia. Revista de Trabajo Social, vol. 12, número extra, pp.131139.

PAVLOSKY, E. (1987): Psicoterapia de grupo en niños $y$ adolescentes, Buenos Aires, Ediciones Búsqueda.

PERALTA, M. (2011): Using musical improvisation in a curricular diversification group with teenagers [tesis de máster], Aalborg University, 〈https:// projekter.aau.dk/projekter/files/53198596/ master_Thesis_Mar_a_Peralta_june_2011.pdf〉.

PÉREZ-VICH, P. (2008): “Musicoterapia cognitivo-conductual con drogodependientes", XIII Congreso Mundial de Musicoterapia, p. 145, Buenos Aires, Akadia.

PERKINS, S. y GRAHAM-BERMANN, S. (2012): "Violence exposure and the development of schoolrelated functioning: Mental health, neurocognition, and learning”, Aggression and Violent Behavior, vol. 17, $\mathrm{n}-1$, pp. 98-98, 〈https://doi.org/10.1016/j.avb.2011.10.001〉.

PORTER, S. et al. (2017): “Music therapy for children and adolescents with behavioral and emotional problems: A randomized controlled trial", Journal of Child Psychology and Psychiatry, vol. 58, nํㅜ 5, pp. 586-594, <https://doi.org/10.1111/ jсpp.12656>.

PUNKANEN, M. (2011): “Improvisational music and perception of emotions in music by people with depression", Jyväskylä studies in humanities, $\mathrm{n}$ 올 153, Jyväskylä, University of Jyväskylä.

RABINOWITCH, T.C.; CROSS, L. y BURNARD, P. (2012): “Longterm musical group interaction has a positive influence on empathy in children", Psychology of Music, vol. 41, nº 4, pp. 484-498, <https:// doi.org/10.1177/0305735612440609〉.

RICKSON, D.J. y WATKINS, W.G. (2003): “Music therapy to promote prosocial behaviors in aggressive adolescent boys. A pilot study", Journal of Music Therapy, vol. 40, nํㅜ 4, pp. 283-301,

RODRÍGUEZ, A. (2017): "Rupturas de convivencia en adopción: claves para una comprensión e intervención reparadoras", en LOIZAGA, F., Adopción en la adolescencia y juventud, Bilbao, Ediciones Mensajero, pp. 357-386.
RODRÍGUEZ DÍAZ, M.C. (2006): “Eficacia de un programa de grupo estructurado en estrategias de afrontamiento para DSPT en adultos y adolescentes en situación de desplazamiento", Universitas Psychologica, vol. 5, nํ 2, pp. 259274.

ROLOCK, N. (2015): “Post-permanency continuity: What happens after adoptions and guardianship from foster care?", Journal of Public Child Welfare, vol, 9, n을, pp. 153-173, 〈https://doi.or $\mathrm{g} / 10.1080 / 15548732.2015 .1021986\rangle$.

ROSAS, C.C. (2001): “Indicadores de cohesión grupal a considerar para su diagnóstico", Acta Odontológica Venezolana, vol. 39, nํㅜ 2, pp. 4-9.

RUSHTON, A. (2004): “A scoping and scanning review of research on the adoption of children placed from public care", Clinical Child Psychology and Psychiatry, vol. 9, nํㅜ 1, pp. 89-106, <https://doi. org/10.1177/1359104504039768〉.

SÁEZ, C. (2010): "Música para las neuronas", Estilos de Vida, 18 de diciembre, <https://cristinasaez. wordpress.com/2010/12/20/musica-yneuronas/>.

SAWYER, R.K. (1999): “Improvised conversations: Music, collaboration, and development", Psychology of Music, vol. 27, n 2, pp. 192-205, 〈https:// doi.org/10.1177/0305735699272009>.

SCHAPIRA, D. et al. (2007): Musicoterapia, abordaje plurimodal, ADIM Ediciones.

SCHÖGLER, B. (2003): "The pulse of communication in improvised music", En Proceedings of the $5^{\text {th }}$ Triennial Conference of the European Society for the Cognitive Sciences of Music (ESCOM5), Hannover, University of Music and Drama.

SEPÚLVEDA, L. (2010): “Las trayectorias de vida y el análisis de curso de vida como fuentes de conocimiento y orientación de políticas sociales", Revista Perspectivas de Trabajo Social, vol. 21, pp. 2753, 〈http://ediciones.ucsh.cl/ojs/index.php/ Perspectivas/article/view/436>

SHAW, M.E. (1983): Dinámica de grupos. Psicología de la conducta de los pequeños grupos, Barcelona, Herder.

SIHVONEN, A.J. et al. (2017): "Music-based interventions in neurological rehabilitation", The Lancet Neurology, vol. 16, $\mathrm{n}-8$, pp. 648-66o, 〈https:// doi.org/10.1016/S1474-4422(17)30168-0〉.

SILBERG, J.L. (2019): El niño superviviente. Curar el trauma del desarrollo y la disociación, Bilbao, Desclée de Brouwer.

SKEWES, K. (2001): The experience of group music therapy for six bereaved adolescents [tesis doctoral], Faculty of Music, University of Melbourne.

SMITH, S.L. (2014): Keeping the Promise. The Case for Adoption Support and Preservation, Nueva York, The Donaldson Adoption Institute.

SWALLOW, M. (2002): “Neurology. The brain: Its music and its emotion, the neurology of trauma", En SUTTON, J.P. (ed.), Music Therapy and Trauma. International Perspectives, Londres, Jessica Kingsley Publishers.

TERCER CIELO (2008): "Yo te extrañaré" [coescrito y coproducido por Juan Carlos Rodríguez], En Hollywood, Disco Hit. 
TOMLINSON, J.; DERRINGTON, P. Y OLDFIELD, A. (2012): Music Therapy in Schools, Working with Children of All Ages in Mainstream and Special Education, Londres, Jessica Kingsley Publishers.

TORRAS DE BEÁ, E. (1996): “Modalidades terapéuticas en la asistencia a niños y adolescentes: la dinámica subyacente", Cuadernos de Psiquiatría y Psicoterapia del Niño y del Adolescente, $\mathrm{n}-21$, pp. 83-104.

VÁZQUEZ-PASTOR, L.J. (2019): “El interés superior del menor de edad en situación de desprotección como principio rector de la actuación de los poderes públicos", Boletín del Ministerio de Justicia, $\mathrm{n}^{\mathrm{0}}$ 2.221, pp. 1-8o.

VINOGRADOV, S. y YALOM, I. (1996): Guía breve de la psicoterapia de grupo, Barcelona, Paidós.

VIVAS, P.; ROJAS, J. y TORRAS, M.E. (2009): Dinámica de grupos, Barcelona, Eureca Media.

WELLS, A. y HAKANEN, E.A. (1991): "The emotional use of popular music by adolescents", Journalism Quarterly, vol. 68, nㅇ 3, pp. 445-454, «https:// doi.org/10.1177/107769909106800315>.

WIGRAM, T. (2005): Improvisación. Métodos y técnicas para clínicos, educadores y estudiantes de musicoterapia, Vitoria-Gasteiz, AgrupArte.

WIGRAM, T.; NYGAARD, I. Y OLE, L. (2005): Guía completa de musicoterapia. Teoría, práctica clínica, investigación y formación, Vitoria-Gasteiz, AgrupArte.

WINNICOTT, D.W. (1959): “El destino del objeto transicional”, En Exploraciones psicoanalíticas I, pp. 72-78. Barcelona, Paidós.

WINNICOTT, D.W. (1970): "La asistencia en internados como terapia”, en WINNICOTT, C.; SHEPHERD, R. y DAVIS, M. (comps.), Deprivación y delincuencia, Barcelona, Paidós, pp. 254-263.

WINNICOTT, D. (1994): Juego y realidad, Barcelona, Gedisa.

YALOM, I. y LESZCZ, M. (2005): The Theory and Practice of Group Psychotherapy, Nueva York, Basic Books.

YÁNEZ, B. (2011): “Musicoterapia en el paciente oncológico", Cultura de los Cuidados, vol. 15, n- 29, pp. 57-73, 〈https://doi.org/10.7184/ cuid.2011.29.07>.

ZAHONERO, A. (2007): “La atención a la diversidad desde la musicoterapia”, Revista Ibero-Americana de Estudos em Educação, vol. 2, noำ 2, pp. 218-235, 〈https://periodicos.fclar.unesp.br/ iberoamericana/article/view/473〉. 